\title{
Grid Sensitivity Study for Slat Noise Simulations
}

\author{
David P. Lockard, ${ }^{*}$ Meelan M. Choudhari ${ }^{\dagger}$ and Pieter G. Buning ${ }^{\dagger}$ \\ NASA Langley Research Center, Hampton, VA 23681 USA
}

\begin{abstract}
The slat noise from the $30 \mathrm{P} / 30 \mathrm{~N}$ high-lift system is being investigated through computational fluid dynamics simulations in conjunction with a Ffowes Williams-Hawkings acoustics solver. Many previous simulations have been performed for the configuration, and the case was introduced as a new category for the Second AIAA workshop on Benchmark problems for Airframe Noise Configurations (BANC-II). However, the cost of the simulations has restricted the study of grid resolution effects to a baseline grid and coarser meshes. In the present study, two different approaches are being used to investigate the effect of finer resolution of near-field unsteady structures. First, a standard grid refinement by a factor of two is used, and the calculations are performed by using the same CFL3D solver employed in the majority of the previous simulations. Second, the OVERFLOW code is applied to the baseline grid, but with a 5th-order upwind spatial discretization as compared with the second-order discretization used in the CFL3D simulations. In general, the fine grid CFL3D simulation and OVERFLOW calculation are in very good agreement and exhibit the lowest levels of both surface pressure fluctuations and radiated noise. Although the smaller scales resolved by these simulations increase the velocity fluctuation levels, they appear to mitigate the influence of the larger scales on the surface pressure. These new simulations are used to investigate the influence of the grid on unsteady high-lift simulations and to gain a better understanding of the physics responsible for the noise generation and radiation.
\end{abstract}

\section{Nomenclature}

$\begin{array}{ll}a & \text { speed of sound } \\ b & \text { span (in or cm) } \\ c & \text { stowed chord (in or cm) } \\ C_{p} & \text { coefficient of pressure } \\ c_{s} & \text { slat chord (in or cm) } \\ f & \text { frequency } \\ M & \text { Mach number, }\left|\mathbf{V}_{o}\right| / a_{o} \\ \text { OASPL } & \text { overall SPL } \\ p & \text { pressure } \\ \text { PSD } & \text { power spectral density }\left(\mathrm{dB} / \mathrm{Hz} \text { or } \mathrm{m}^{2} / \mathrm{s}^{2} / \mathrm{Hz}\right) \\ \mathrm{Re}_{c} & \text { Reynolds number, }\left|\mathbf{V}_{o}\right| c / \nu_{o} \\ \mathrm{rms} & \text { root mean square } \\ S & \text { distance along trajectory of cove shear layer } \\ \mathrm{SPL} & \text { sound pressure level }(\mathrm{dB}) \\ S t & \text { Strouhal number, } f^{*} c_{s} /\left|\mathbf{V}_{o}\right| \\ \mathrm{TKE} & \text { turbulence kinetic energy }\end{array}$

$$
\begin{array}{ll}
u, v, w & \text { Cartesian fluid velocity components } \\
U, V, W & \text { time-averaged velocity components } \\
|\mathbf{V}| & \text { magnitude of velocity vector } \\
\left|\mathbf{V}_{2 D}\right| & \text { planar velocity mangitude } \\
x, y, z & \text { Cartesian coordinates } \\
\text { Greek: } & \\
\beta & \text { yaw angle (deg) } \\
\rho & \text { fluid density } \\
\nu & \text { kinematic viscosity }\left(\mathrm{ft}^{2} / \mathrm{s} \text { or } \mathrm{m}^{2} / \mathrm{s}\right) \\
\text { Superscript: } \\
\begin{array}{l}
\text { perturbation quantity }\left(\mathrm{e} . \mathrm{g} ., \rho^{\prime}=\rho-\rho_{\infty}\right) \\
\text { dimensional quantity }
\end{array} \\
\text { Subscript: }
\end{array}
$$

$\begin{array}{ll}\infty & \text { dimensionless free-stream quantity } \\ o & \text { dimensional free-stream reference quantity }\end{array}$

\section{Introduction}

The non-propulsive (or airframe) sources of aircraft noise include high-lift devices (e.g., the leading-edge slat and trailing-edge flaps) and the aircraft undercarriage. The ranking of these sources is configuration dependent; however, both model-scale tests ${ }^{1-7}$ and flyover noise measurements ${ }^{8}$ have identified the leading-edge slat as a prominent source of airframe noise during aircraft approach. The reduction of airframe noise is an important goal of the NASA Fundamental Aeronautics Program's Subsonic Fixed-Wing Project, which is supporting a combined experimental and computational effort to better understand the source of slat noise. The slat noise spectrum is typically broadband, but may include one or more narrower peaks associated with aerodynamic and/or aeroacoustic resonances. Previous measurements indicate that the broadband spectrum has a maximum between Strouhal numbers of one and three (where the Strouhal number is define as $\left.f^{*} c_{s} /\left|\mathbf{V}_{o}\right|\right)$ is based on the freestream velocity $\left|\mathbf{V}_{o}\right|$ and slat chord $\left.c_{s}\right)$. The acoustic directivity for this

\footnotetext{
*Aerospace Technologist, Computational AeroSciences Branch, Mail Stop 128, Senior Member, AIAA

$\dagger$ Aerospace Technologist, Computational AeroSciences Branch, Mail Stop 128, Associate Fellow, AIAA
} 
frequency range exhibits a peak in the lower aft quadrant ${ }^{9}$ in addition to a peak in the upper forward quadrant, which is of less practical interest. The overall sound pressure level (OASPL) for slat noise sources has been shown to scale with $M_{o}^{4.5}$ by Dobrzynksi ${ }^{9}$ and $M_{o}^{5}$ by Guo, ${ }^{10,11}$ where $M_{o}$ denotes the free-stream or flight Mach number. Mendoza ${ }^{6}$ found that the overall sound pressure level for slat noise sources scaled with $M,{ }^{5}$ but mid to high frequencies scaled with something between $M_{o}^{4}$ and $M_{o}^{5}$. However, as discussed in Refs. 9 and 11, the physical mechanisms underlying the observed characteristics of slat noise have not been fully explained as yet.

An essential ingredient to developing physics-based predictions of airframe noise involves synergistic combinations of experiments and numerical simulations for subcomponents. Recent studies have provided a number of useful physical insights into the noise source mechanisms that are responsible for the dominant features of the measured slat- and flap-noise spectra. Specifically, the high-frequency spectral hump in the slat noise measurements at NASA ${ }^{2,5}$ has been attributed to vortex shedding from a finite thickness slat trailing edge. ${ }^{12,13}$ The broadband component of slat noise at lower frequencies has been linked with the interaction between unsteady vortical structures in the slat cove region and the adjacent features of the high-lift geometry (viz., the slat trailing edge and the gap region between the slat and the main element). ${ }^{14-16}$ The two-dimensional (2-D) computations of this type helped clarify the cause-effect relationships between the near-field flow structures and the far-field noise; however, a further assessment of these computations ${ }^{17}$ indicated excessively energetic vortical structures in comparison with the PIV measurements. ${ }^{18}$ Three-dimensional (3D) computations over a narrow portion of the model $\operatorname{span}^{19}$ led to significant improvement in that regard, yielding a favorable comparison with the PIV measurements. ${ }^{18}$ The importance of 3-D fluctuations in determining the unsteady dynamics within the cove region has also been confirmed via computations for other high-lift configurations and by using alternative numerical algorithms. ${ }^{20,21}$

The near-field fluctuations within the slat cove have been investigated experimentally ${ }^{18}$ by using the $30 \mathrm{P} / 30 \mathrm{~N}$ model. The 30P/30N model tested in the Basic Aerodynamic Research Tunnel (BART) at NASA Langley Research Center represents a generic, three-element, zero-sweep high-lift configuration with slat and flap deflections of 30 degrees each. The slat chord and flap chord of the model are equal to $15 \%$ and $30 \%$, respectively, of the 18 in $(0.457 \mathrm{~m})$ stowed chord. For the approach configuration, the slat gap is $2.95 \%$; the flap gap is $1.27 \%$; and the slat and flap overhang settings are equal to $-2.95 \%$ and $0.25 \%$ of the stowed chord, respectively. Reference 22 provides a definition of these rigging parameters. At the test Mach number of 0.17, the Reynolds number, $\operatorname{Re}_{c}$, based on the stowed chord of the BART model is 1.71 million. While this Reynolds number is substantially lower in comparison with full-scale applications, the BART experiment is still suitable for validating numerical predictions of the slat cove noise sources as described in Ref. 19. The BART measurements ${ }^{18}$ consist of steady surface pressure measurements and extensive 2-D particle image velocimetry (PIV) data within the mid-span plane of the model.

In CFD, the effect of the spanwise extent of the computational domain was investigated by Lockard and Choudhari ${ }^{23}$ by increasing the span from 1" (37.3\% of the slat chord as used in Ref. 19) to 6" (226\% of the slat chord or $15 \%$ of the model span) while maintaining the same spanwise resolution. The simulations with the longer span indicated that the spanwise surface pressure correlations do not become smaller than 0.05 until around 2" (74.6\% of the slat chord). The longer span also enabled predictions of the far-field noise without excessive assumptions about the near-field spanwise behavior. However, the spanwise correlation length of the acoustic signals was found to be on the order of a slat chord, so a much longer span than even $226 \% c_{s}$ would be needed to adequately propagate noise to the far-field at frequencies near the peak in the broadband signal. Nonetheless, the near-field unsteadiness that gives rise to the noise can be adequately modeled with a 2" span and allows the shorter span to be used in parametric studies examining the source mechanism.

Although the slat geometry is basically 2-D, most modern aircraft have swept wings which will produce a spanwise flow. Imamura et $\mathrm{al} .^{24}$ performed simulations of both swept and unswept wing configurations, but their results for the near-field unsteadiness were inconclusive as to the effect of the cross flow because the observed differences were deemed to be within their uncertainty. Dierke et al. ${ }^{25}$ calculated the noise from the $30 \mathrm{P} / 30 \mathrm{~N}$ by using a steady RANS solution to provide input to a stochastic turbulence method that calculated an acoustic source for a computational aeroacoustics simulation. Their 3-D simulations without sweep were able to reasonably approximate earlier 2-D computations by Bauer and Ewert ${ }^{26}$ and also showed reasonable agreement with the simulations of Lockard and Choudhari. ${ }^{23}$ Their cases with sweep exhibited similar spectral shapes to unswept cases, but tonal features were somewhat diminished. Lockard and Choudhari ${ }^{27}$ also simulated the $30 \mathrm{P} / 30 \mathrm{~N}$ with two different freestream flows that included an imposed spanwise velocity to examine the effects of sweep. Their results indicated that the fluctuations and noise scaled primarily with the velocity normal to the leading edge rather than the total velocity. Furthermore, with this scaling, the spectral shape was relatively unchanged when sweep was imposed. They did observe different behavior in the tonal features between two cases with a spanwise flow. A case with a lower streamwise velocity and lower Reynolds number did not exhibit as pronounced tonal features. However, their simulations varied both the Mach and Reynolds numbers simultaneously in an attempt to keep the same boundary layer characteristics in the cross flow cases. Hence, the independent effects of the Mach number, Reynolds number, and cross flow could not be determined. In a subsequent paper, Lockard and Choudhari ${ }^{28}$ 
examined the independent effects of Mach numbers in the range 0.13 to 0.25 and Reynolds numbers between 1.209 and 2.418 million. They found that the noise scaled approximately with the fifth power of the velocity, but had almost no dependence on the Reynolds number. In all of these cases, the tonal features were evident.

The influence of the angle of attack was examined by Choudhari et al. ${ }^{29}$ The angle of attack was varied from $3^{\circ}$ to $8^{\circ}$, with the broadband noise decreasing along with a corresponding rotation of the directivity pattern as the angle of attack increased. However, the general character of both the near-field unsteadiness within the slat cove region and the far-field acoustics were found to remain unchanged with the variation in the angle of attack. Furthermore, the tonal behavior was observed at all angles of attack.

Numerous experiments ${ }^{30-32}$ have observed tonal features in slat spectra from small-scale models at low Reynolds numbers, and some have had success reducing or eliminating them by using tripping. The tonal features observed in $30 \mathrm{P} / 30 \mathrm{~N}$ simulations have been robust for the modest range of Reynolds numbers investigated previously. However, there is some experimental evidence that higher Reynolds numbers may be required to see an effect. In experiments ${ }^{5}$ conducted in the Low Turbulence Pressure Tunnel at NASA Langley, the noise from the Energy Efficient Transport (EET) 3-element high-lift system was examined for Reynolds numbers from 3.6 to 19 million. The noise was found to be relatively insensitive to Reynolds number variations above 7.2 million, although almost all of the differences in the slat spectra at a $R e_{c}$ of 3.6 million were restricted to a high-frequency spectral hump attributed to trailing-edge shedding. ${ }^{12,13}$ The tonal features at all frequencies in $30 \mathrm{P} / 30 \mathrm{~N}$ simulations ${ }^{33}$ have been found to be relatively insensitive to the computational Reynolds number.

The 30P/30N configuration has been introduced as a new slat category for the Third Benchmark problems for Airframe Noise Configurations (BANC-III) workshop. ${ }^{a}$ However, the geometry is slightly different from what has been used previously. The region in the vicinity of the slat trailing edge was thickened to allow Kulite unsteady pressure transducers to be flush mounted to the underside of the slat. Experiments have been performed at both Florida State University and JAXA to acquire the unsteady pressures and their spanwise correlations providing additional validation data for the computations. Furthermore, the thicknesses of all trailing edges remain finite and have not been artificially sharpened for computational expediency. The current simulations employ a grid generated for the BANC-II version of the $30 \mathrm{P} / 30 \mathrm{~N}$ configuration, with a baseline resolution that closely resembles that of the previous simulations performed by the authors. ${ }^{27,28,33}$

Two calculations on the baseline grid have been completed by using CFL3D: ${ }^{34}$ investigating the effect of employing a RANS/LES switch uniformly throughout the domain, and forcing the region around the flap to revert to RANS. Unsteadiness develops around the flap, but such phenomena are not the focus of the current study. Hence, in an attempt to isolate the slat noise in the resulting acoustics, pure RANS is used in the flap region to suppress unsteadiness. Calculations on a grid uniformly coarsened/refined by a factor of 2 in each coordinate direction have also been completed.

Calculations using the OVERFLOW ${ }^{35}$ solver have also been performed. Using OVERFLOW not only allows the investigation of an overset grid technique with higher-order spatial operators, but in the future may allow an automated, feature-based grid adaption methodology to be employed. The current OVERFLOW simulation is on the baseline grid with a fifth-order upwind spatial operator for the inviscid terms.

\section{Computational Simulations}

The simulations use an extruded 2-D geometry (in the $x-y$ plane). Table 1 lists the parameters for the case under investigation. The velocities in the table and this paper are nondimensionalized by the free-stream speed of sound, and, therefore are equivalent to Mach numbers. The freestream vertical and spanwise velocities are zero, so $\left|\mathbf{V}_{\infty}\right|=U_{\infty}$. The Reynolds number is 1.71 million.

Table 1. Flow Parameters.

\begin{tabular}{|c|c|c|c|c|c|}
\hline$\left|\mathbf{V}_{\infty}\right|$ & $U_{\infty}$ & $V_{\infty}$ & $W_{\infty}$ & $\beta$ & $\operatorname{Re}_{c} \times 10^{6}$ \\
\hline 0.17 & 0.17 & 0.0 & 0.0 & $0^{\circ}$ & 1.71 \\
\hline
\end{tabular}

The computational procedure closely follows that used for the simulations in Refs. 19, 23, 27, and 28. Version 6 of the CFL3D ${ }^{36}$ flow solver developed at NASA Langley Research Center is used to solve the 3-D, time-dependent, NavierStokes equations using a finite-volume formulation; the full viscous fluxes in all three grid coordinates are retained during the present simulations. A hybrid approach is used where the RANS equations are solved in regions where the grid is insufficient to resolve the unsteady turbulent eddies, such as in boundary layers around solid bodies; and an implicit

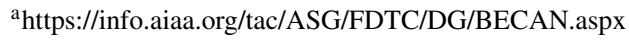


large eddy simulation (LES) is performed in regions where the grid can resolve the eddy dynamics. The simulations used a third-order upwind scheme with flux-difference splitting, which has been shown to provide second order spatial accuracy in previous applications of CFL3D. ${ }^{36}$ Based on the spanwise correlation results of Ref. 23, a spanwise extent of 2" (74.6\% of the slat chord) is used in the simulations.

The OVERFLOW ${ }^{35}$ calculation uses a fifth-order upwind spatial discretization with the HLLC flux scheme for inviscid terms the right hand side. The ARC3D diagonalized Beam-Warming scalar pentadiagonal scheme is used for the left hand side. A zonal turbulence model was employed with pure RANS being used around the flap and a Delayed Multi-Scale Shear Layer Transport (SST) mode ${ }^{37}$ over the rest of the domain. The Delayed Multi-Scale method is a DDES variant for the SST turbulence model that was introduced by Strelets ${ }^{38}$ and it was found to produce eddy viscosity levels that were similar to those produced by CFL3D. The baseline CFL3D grid was modified to have overlap regions so that it could be used as an overset grid.

\section{A. Configurations and Grids}

The $30 \mathrm{P} / 30 \mathrm{~N}^{22}$ high-lift system was simulated in free air without any wind-tunnel walls. The trailing edge of each of the three elements has a finite thickness. However, previous simulations followed the approach taken in Ref. 23 where, for computational efficiency, all of the trailing edges (including the cusp or first edge of the slat) were artificially sharpened while preserving the camber of the respective sections. The new calculations in this work maintain the blunt, finite-thickness trailing edges.

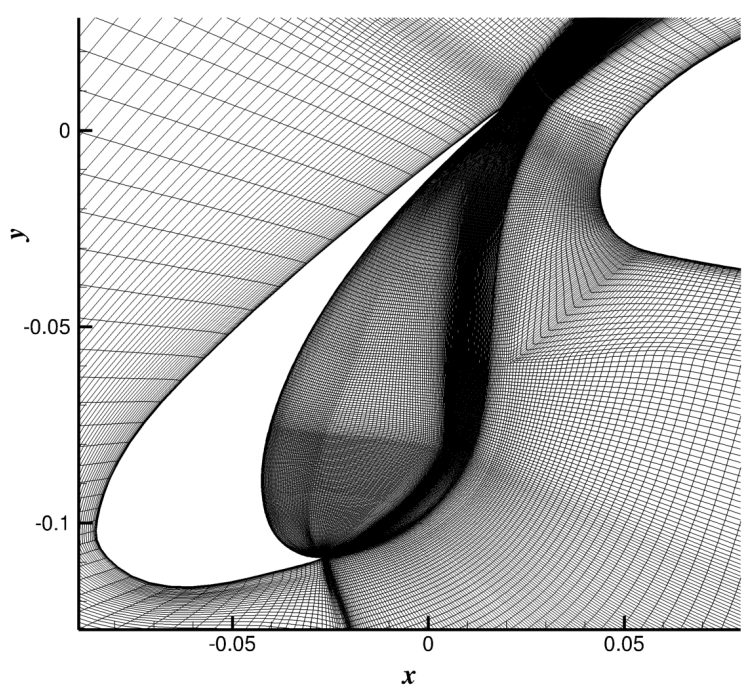

(a) Sharp

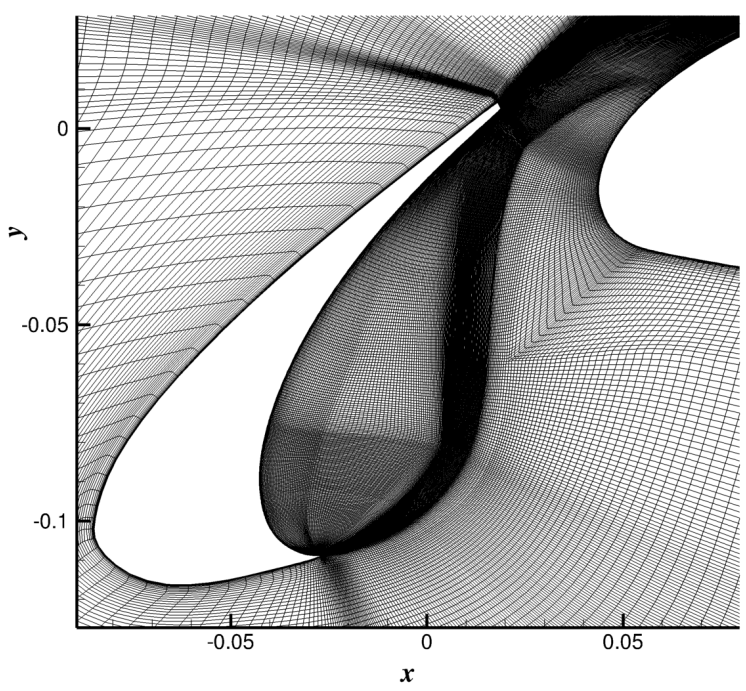

(b) Blunt

Figure 1. Planar view of grid around the slat (every other point).

The investigated configuration corresponds to $4^{\circ}$ angle of attack in BART, ${ }^{18}$ which approximates the mean slat loading for a free-flight configuration at $5.5^{\circ}$ angle of attack. The block structured, $x-y$ planar grid shown in Fig. 1(a) with sharp edges contains a total of 480,000 points in 77 blocks. The new grid in Fig. 1(b) with the blunt edges has 567,000 points in 93 blocks. Care was taken so that the first point off the solid surfaces was at $y^{+}<1$. To generate the 3-D grids, the planar mesh was replicated along the span over a distance of 0.746 slat chords using 129 points for a total grid point count of 62.0 and 73.2 million, respectively. A refined grid was also created for the blunt slat configuration with double the points in each coordinate direction, yielding 585 million grid points. Most of the block interfaces are point-matched with a one-to-one correspondence from each side. Patched interfaces, where the grid is coarsened going from one block to its neighbor, were also employed but were restricted to regions away from the slat. The baseline grid was developed for a nominal Reynolds number of 1.71 million, but still provides good resolution with $y^{+}<1$ for a $\operatorname{Re}_{c}$ of 7.2 million. At a $\operatorname{Re}_{c}$ of 12 million, $y^{+}$does exceed unity in some localized regions, but $y^{+}<2$ is still maintained throughout the surface of each airfoil element.

The baseline CFL3D grid was modified to merge many of the blocks, then the Chimera grid tools were used to extend the remaining blocks to have overlap regions. The parallelization in CFL3D distributes blocks across CPU cores, whereas OVERFLOW can split blocks internally. Furthermore, OVERFLOW can be run in a mixed OPENMP/MPI 
mode where some of the cores can efficiently work together on a given block. The original and modified version of the baseline grid can be seen in Fig. 2.

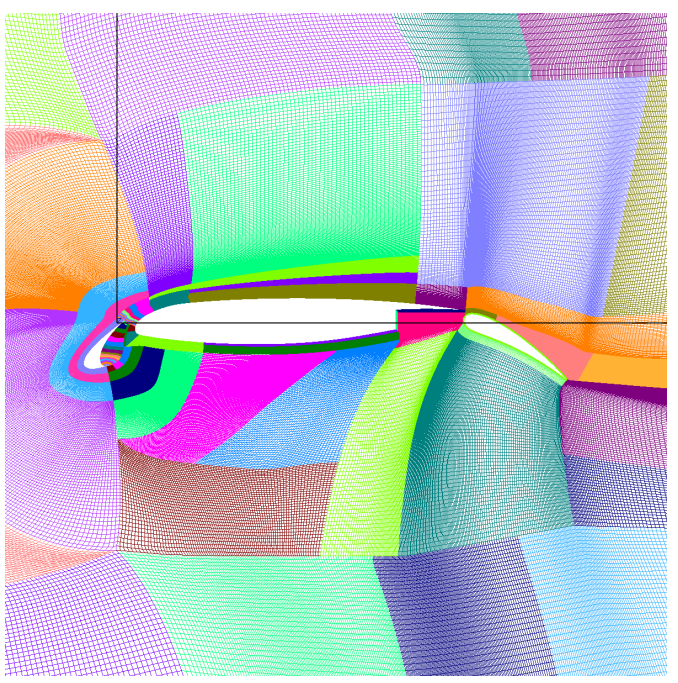

(a) Original

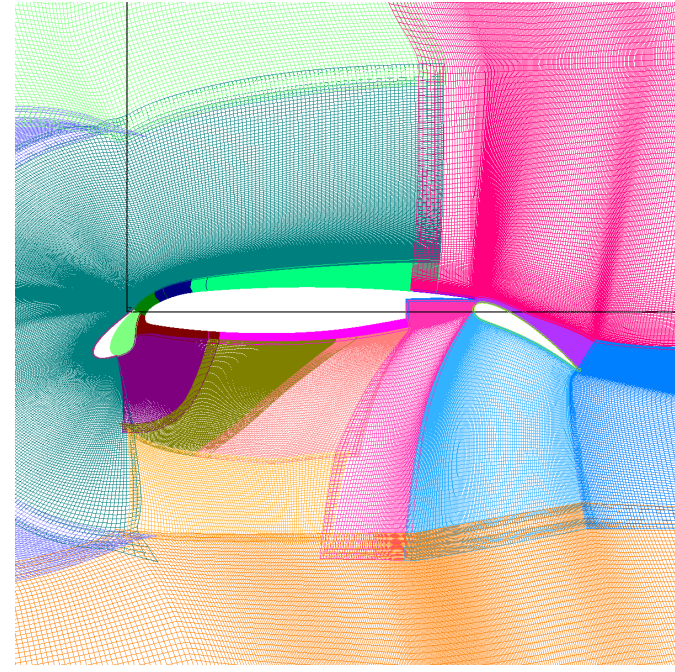

(b) Merged and overlapped

Figure 2. Original baseline grid and one modified for OVERFLOW.

Characteristic boundary conditions were used along the far-field boundaries in the $x-y$ plane, except for extrapolation from the interior at the downstream boundary. The circular outer boundary was located 12 airfoil chords from a point in the slat cove. Periodic boundary conditions were used across the spanwise boundaries of the computational domain. No attempt was made to resolve the end effects associated with the presence of tunnel side walls in the experiments. No-slip conditions were imposed at the solid surfaces, along with an adiabatic wall thermal boundary condition.

In CFL3D a DDES formulation ${ }^{\mathrm{b}}$ of the two-equation Shear Stress Transport (SST) model of Menter ${ }^{39}$ was used to capture the mean flow behavior of the unresolved scales of motion in regions away from the slat cove region. In previous simulations the turbulence production terms in the turbulence transport equations were switched off within the cove region ${ }^{19}$ to eliminate the excessive diffusive effects of the turbulence model on the resolved unsteady flow structures. The designation SST-QL ${ }^{40}$ refers to the combination of the SST turbulence model and a quasi-laminar cove. Due to a lack of experimental transition data along the solid surfaces, as well as to maintain consistency with the previous simulations, ${ }^{15-17}$ the flow within the Reynolds-Averaged Navier Stokes (RANS) regions was treated as fully turbulent. However, the turbulence model produced very low turbulent eddy viscosity in certain regions, such as on the upstream portion of the slat. Previous computations ${ }^{28}$ have also been performed by using a modified version of the DDES ${ }^{40}$ and the Spalart-Allmaras ${ }^{41}$ turbulence model, and no significant differences were observed with the quasi-laminar approach.

CFL3D employs a dual-time-stepping algorithm where subiterations are used to converge the solution within each time step. Fifteen subiterations were used per time step to reduce the residual by a minimum of three orders of magnitude. The time step was $d t^{*} a_{o} / c=0.0016232$ or $d t^{*}\left|\mathbf{V}_{\mathbf{o}}\right| / c=0.00028$ which results in 453 time steps per period at a frequency of $1 \mathrm{kHz}(S t=1.18)$. The corresponding convective scale for a particle traveling with the flow to traverse the stowed chord of the airfoil is 3,573 time steps. The time step used in the current simulations corresponds to approximately 20 time steps per period of the peak frequency of the high-frequency vortex shedding behind the slat trailing edge. Thus, the temporal resolution is deemed to be the bare minimum to resolve the high-frequency peak. However, based on the time-step study performed in Ref. 23, the step size used in the current simulations should be sufficient to resolve the broadband component of the slat fluctuations, which is the focus of the present study. OVERFLOW was run with the same dual-time algorithm and time step as CFL3D. However, the subiterations had to be increased to 40 because of an instability that developed at the frequency corresponding to one acoustic wavelength in the spanwise direction. This instability eventually overwhelmed the solution, but not until after sufficient samples were collected.

The simulation procedure includes several steps. First, a steady-state computation was used to set up the basic mean flow, followed by an unsteady calculation with random suction and blowing applied to different spanwise and azimuthal sections of the slat in order to accelerate the onset of 3-D, unsteady flow structures. The forcing did not exceed 3\% of the freestream velocity. The forcing was turned off after significant unsteadiness was observed, typically a few hundred time steps into the unsteady calculation. The simulation was then run for at least 30,000 time steps (i.e., more than

${ }^{\mathrm{b}}$ http://cfl3d.larc.nasa.gov/Cfl3dv6/cfl3dv6.html, New Features, DES and DDES Capability, Oct. 2012. 
eight convective time units) to allow the transient flow field to wash out before collecting time records. After this phase, well-resolved, unsteady structures develop in the slat cove region. There is also unsteadiness associated with a separated region on the flap. The grid is too coarse to resolve the unsteady flow around the flap, and reducing or eliminating these fluctuations is advantageous to isolate the effects of the unsteady flow around the slat. To be consistent with the coarser spatial grid, the turbulence model was modified to force pure RANS for $x^{*} / c>0.7$ (near the beginning of the main wing cove). These simulations are denoted as SST DDZ for zonal DDES. Averaged flow quantities were produced by timeaveraging over a minimum of 39,000 time steps. To increase the number of averages, a second averaging process was performed in the spanwise direction. Although shear layers can exhibit inhomogeneous spanwise behavior, assuming spanwise homogeneity of the flow statistics is consistent with the observations of this particular flowfield.

\section{Near-Field Results}

The 6 different simulations that have been performed are summarized in Table 2. The time-averaged coefficient of pressure, $C_{p}=<2\left(p^{*}-p_{o}\right) /\left(\rho_{o} U_{o}^{2}\right)>$, on the solid surfaces is presented in Fig. 3. Results are presented from 3 calculations using CFL3D: old baseline grid with sharpened trailing edges and quasi-laminar turbulence treatment (SSTQL Sharp), ${ }^{23}$ new baseline grid with DDES hybrid turbulence model (SST DDES), and new baseline grid with DDES hybrid turbulence model and zonal RANS for $x^{*} / c>0.7$ (SST DDZ). The data was generated by averaging over time and then averaging over the span by assuming that the flow is homogeneous in that direction. Overall, the agreement is fairly good, although the new grid is producing slightly higher suction values on the upper surface of the slat. Also, the flap separation is a little less abrupt in the SST DDES simulation compared with the other two which employ RANS over the flap. No experimental data for the free-air configuration is available, but the $5.5^{\circ}$ angle of attack for the simulations was chosen to match the mean lift on the slat from the closed-wall BART experiments ${ }^{18}$ performed at an angle of attack of $4^{\circ}$. Results from the grid refinement study are presented in Fig. 4, including those from the coarse, baseline, and fine grids with CFL3D as well as the baseline grid with OVERFLOW. The magnitude of the $C_{p}$ values from the coarse grid on the suction side are a little below those of the other calculations; but, otherwise, the results for the various cases are nearly the same.

Table 2. Case definitions.

\begin{tabular}{|l|l|l|l|l|}
\hline Designation & Code & Grid & Resolution & Turbulence Model \\
\hline SST-QL & CFL3D & Sharp TE & Baseline & Quasi-laminar SST \\
\hline SST DDES & CFL3D & Blunt TE & Baseline & SST DDES \\
\hline SST DDZ Coarse & CFL3D & Blunt TE & Coarse (2x) & Zonal SST DDES \\
\hline SST DDZ & CFL3D & Blunt TE & Baseline & Zonal SST DDES \\
\hline SST DDZ Fine & CFL3D & Blunt TE & Fine (2x) & Zonal SST DDES \\
\hline SST DDZ OVERFLOW & OVERFLOW & Blunt TE & Baseline & Zonal SST Multiscale \\
\hline
\end{tabular}

A comparison of the calculated $C p_{r m s}^{\prime}$ is shown in Figs. 5 and 6. The $C p_{r m s}^{\prime}$ on the flap is somewhat high for the pure DDES simulation because of the unsteadiness associated with shedding from the flap in the separated region, but forcing RANS around the flap greatly reduced the fluctuations. Employing RANS around the flap in the OVERFLOW simulation was not quite as effective as the CFL3D simulations at eliminating the flap unsteadiness.

A close-up of $C p_{r m s}^{\prime}$ over the slat is shown in Fig. 7. The fluctuations initially reach a maximum near the reattachment point in the slat cove at $x^{*} / c=0.005$. The curves do not collapse in that region, with the coarse grid and the case with sharpened edge exhibiting the highest levels. The coarse grid produces fluctuations that are roughly $30 \%$ larger than that of the fine grid. The fine grid and OVERFLOW fluctuation levels are remarkably similar and also the lowest in magnitude. The surface pressure fluctuation levels in the cove decrease in magnitude as the grid is refined, whereas the pressure fluctuations associated with the strength of the vortex shedding at the slat trailing edge $\left(x^{*} / c=0.02\right)$ increases with grid refinement. In general, the fluctuation levels typically increase with grid refinement while the large scales associated with the phenomena are being adequately resolved. Once they are sufficiently captured in the simulation, further refinement typically introduces smaller scales that act to dissipate some of the energy in the larger scales. In this problem, the shedding at the trailing edge is a very high frequency phenomena that needs a fine grid to even begin to model the phenomena, whereas the slat cove fluctuations occur at relatively low frequencies, and the finer grids are able to resolve scales well beyond those of the peak energy-containing eddies.

Contours of the magnitude of the mean planar velocity $\left|\mathbf{V}_{2 D}^{*}\right|$, nondimensionalized by $U_{o}$, are presented in Fig. 8. The points and lines identify locations for more detailed comparisons. The velocity distributions are visually quite 


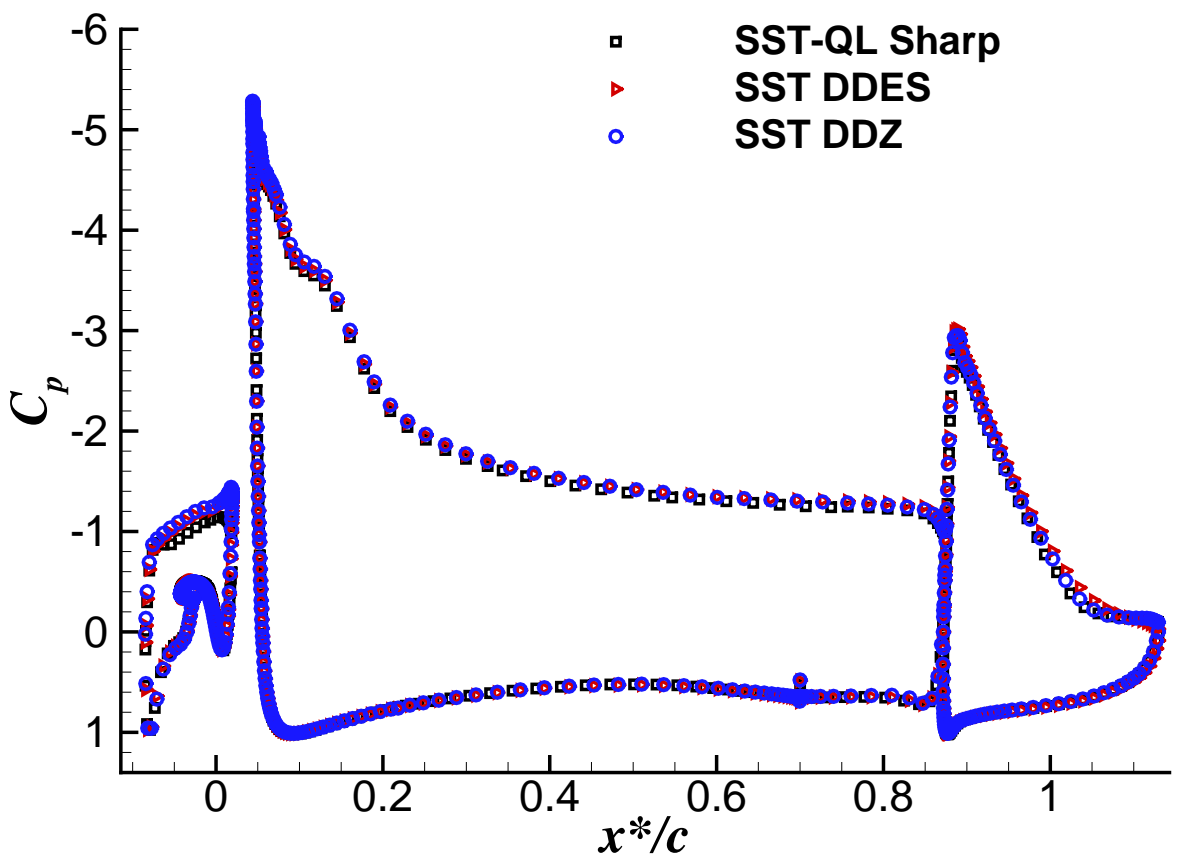

Figure 3. Time-averaged coefficient of pressure on the airfoil. Sharp/Blunt refer to the thickness of the trailing edges.

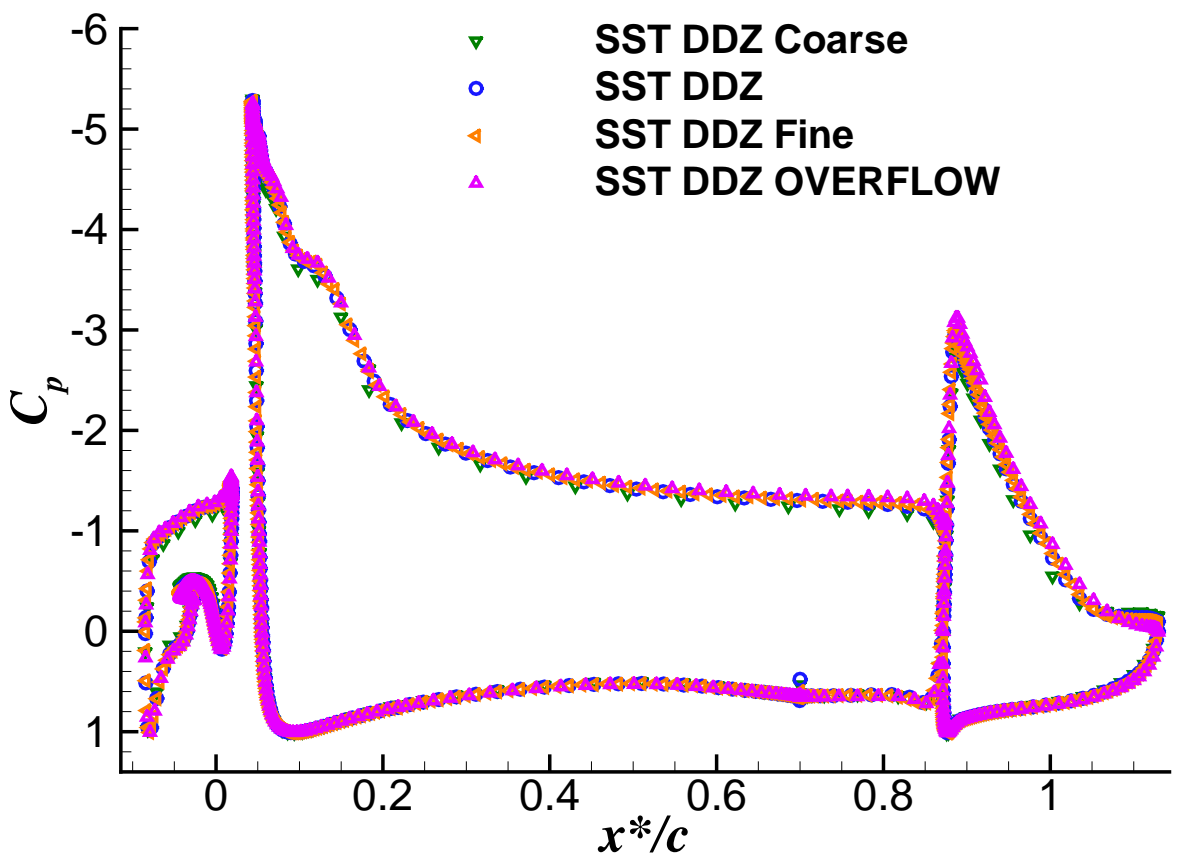

Figure 4. Time-averaged coefficient of pressure on the airfoil.

similar for all the computations. The trajectory of the shear layer is also nominally the same as indicated by the purple streamline superimposed in the figures. The SST DDES and OVERFLOW results are not shown as they are visually indistinguishable from the SST DDZ and fine grid solutions, respectively.

The values of the spanwise vorticity and streamwise velocity on the upstream four line cuts (L1, L2, L3, L4) shown in Fig. 8 are plotted in Fig. 9. Here, the result from the old grid with the sharp trailing edge agrees quite well with the coarse grid calculation, whereas all of the other results are quite similar to each other indicating that the modification in slat geometry had an insignificant effect on the important aspects of the flow for slat cove noise generation. The center 


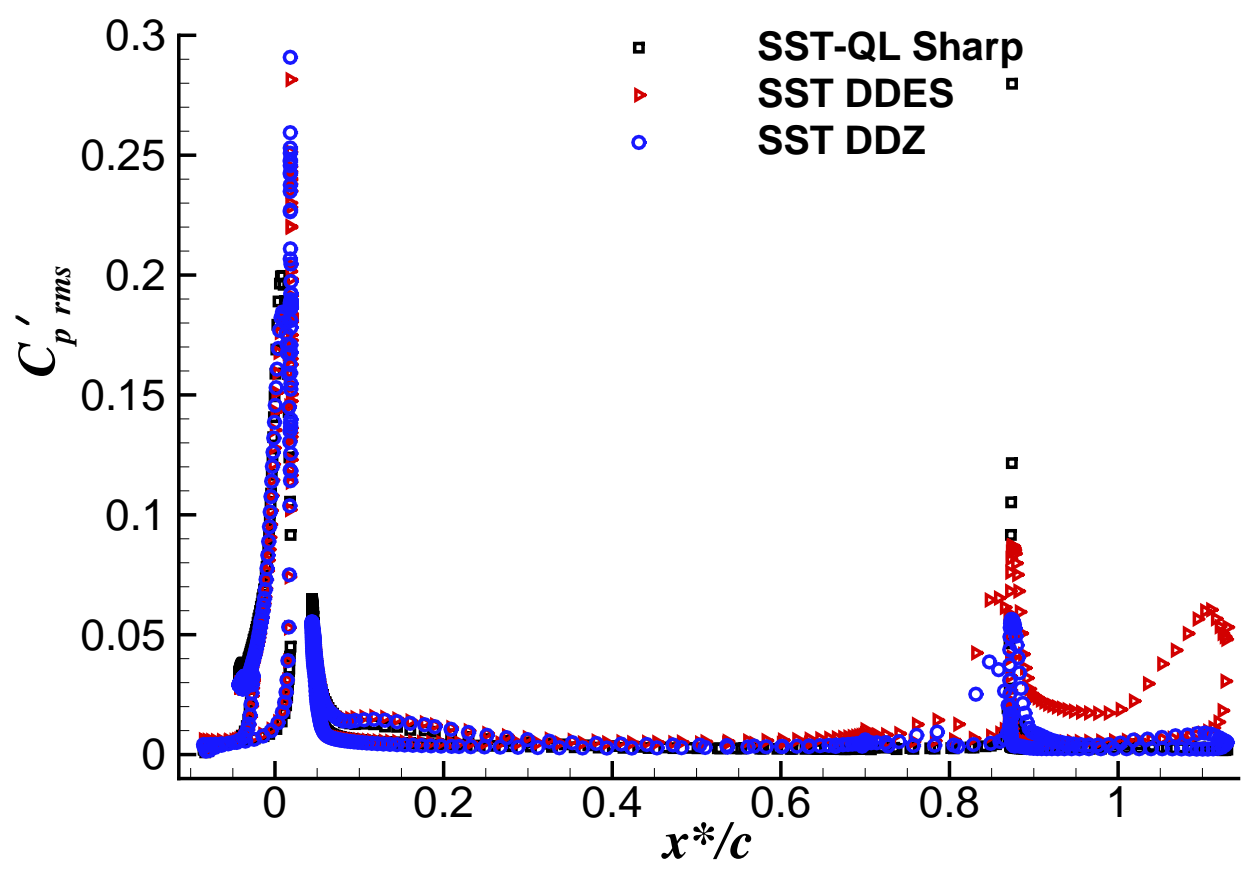

Figure 5. RMS of the fluctuating coefficient of pressure on the airfoil. Sharp refers to the thickness of the trailing edges.

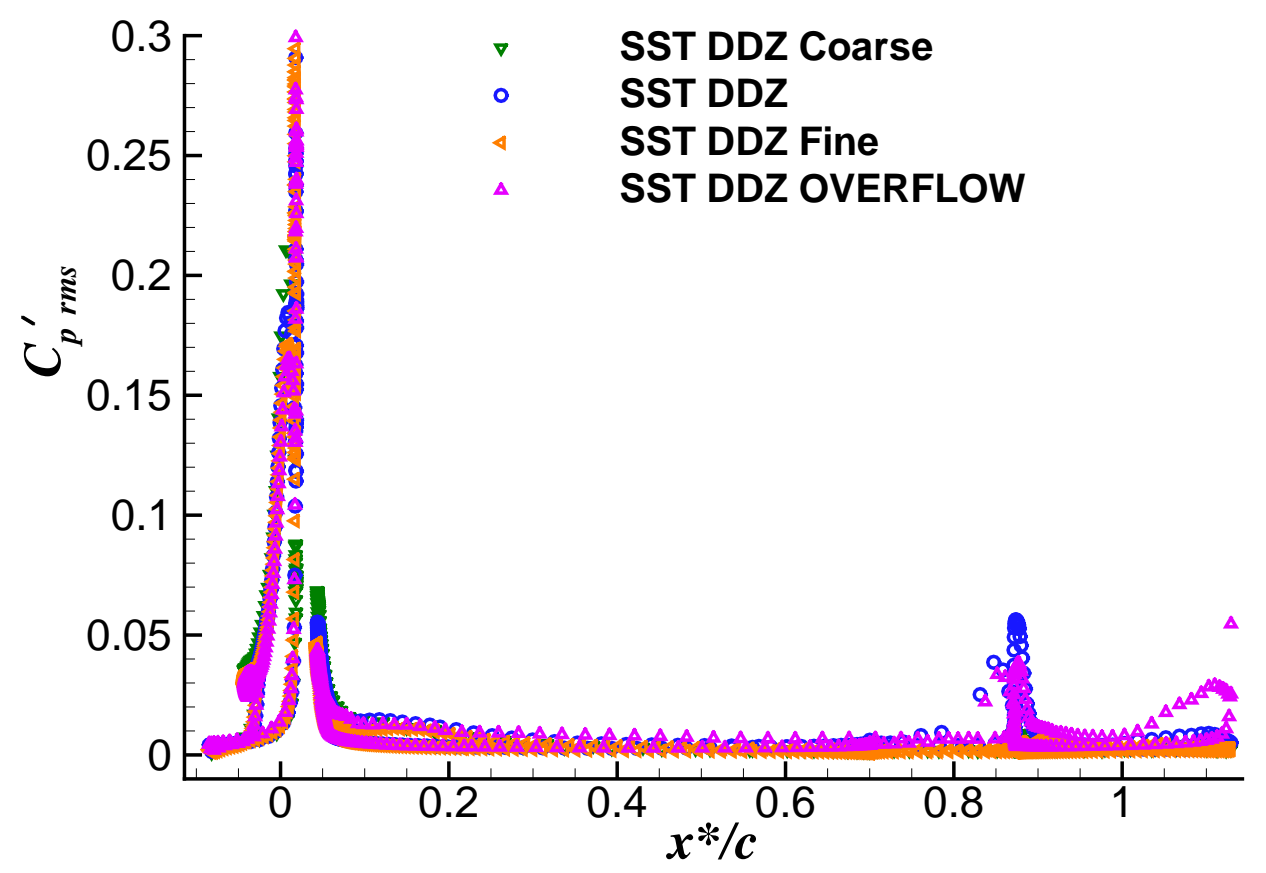

Figure 6. RMS of the fluctuating coefficient of pressure on the airfoil.

of the shear layer is slightly further downstream on the coarser mesh, and the velocity difference across the shear layer is slightly higher resulting in a larger mean vorticity. On the finer meshes, the shear layer spreads faster which smooths out the velocity distribution across the shear layer. The differences are quite subtle, and only really show up in the detailed line plots and not in the flood contours.

However, the contours of the 3-D turbulence kinetic energy (TKE), $\frac{1}{2}\left(\left\langle u^{\prime} u^{\prime}\right\rangle+\left\langle v^{\prime} v^{\prime}\right\rangle+\left\langle w^{\prime} w^{\prime}\right\rangle\right.$ ), normalized by the square of the streamwise velocity, $U_{o}^{2}$, reveals some differences as seen in Fig. 10. Note that these contours represent the resolved portion of the turbulent fluctuations as they do not include any contributions from the 


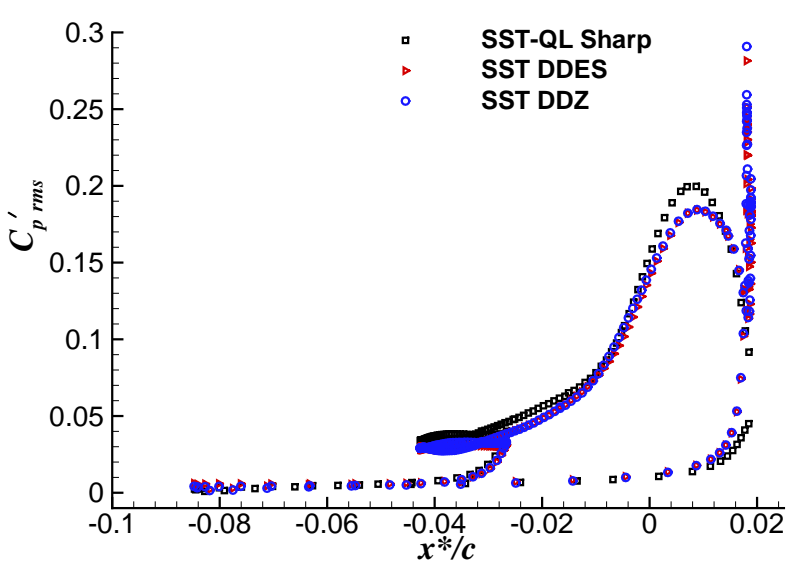

(a)

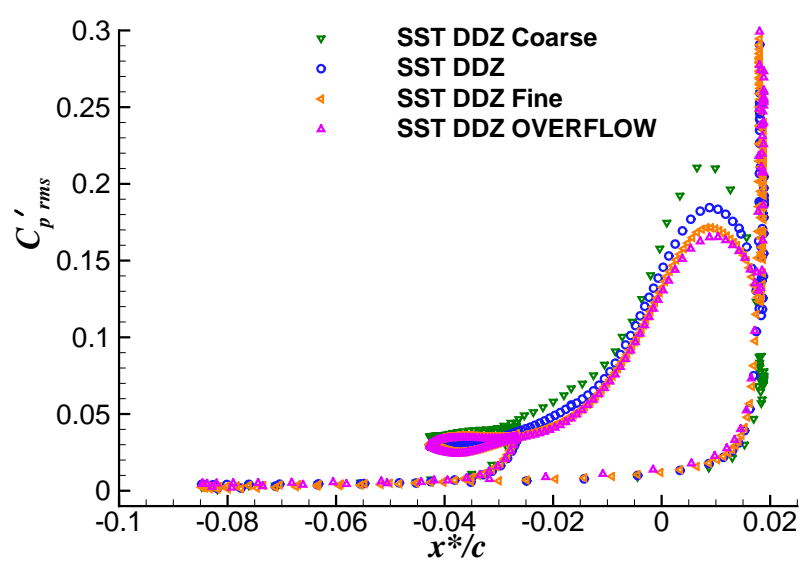

(b)

Figure 7. RMS of the fluctuating coefficient of pressure on the slat. Sharp refers to the thickness of the trailing edges.

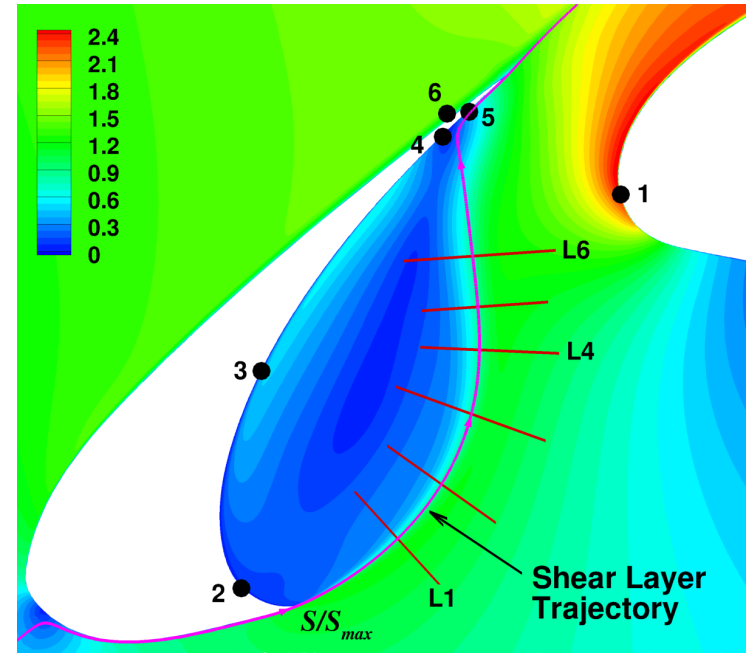

(a) SST-QL Sharp

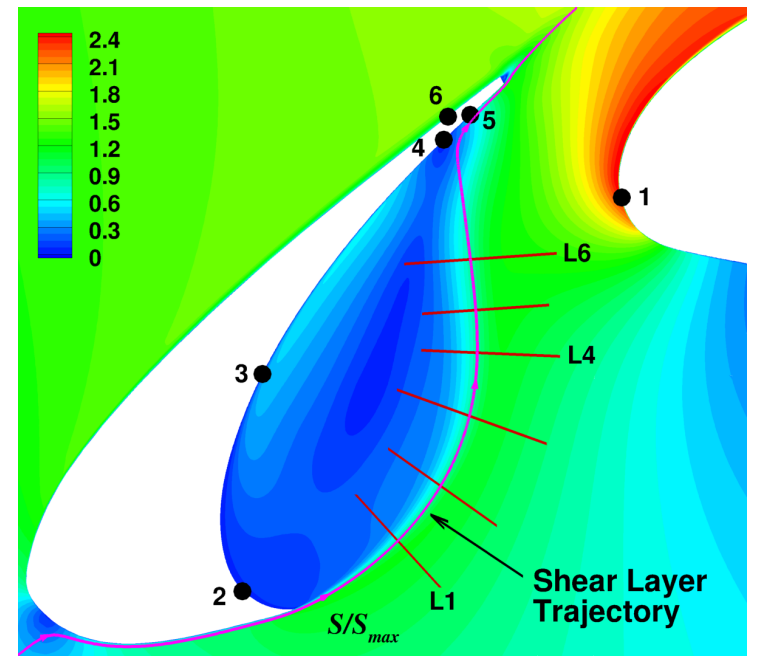

(c) SST DDZ

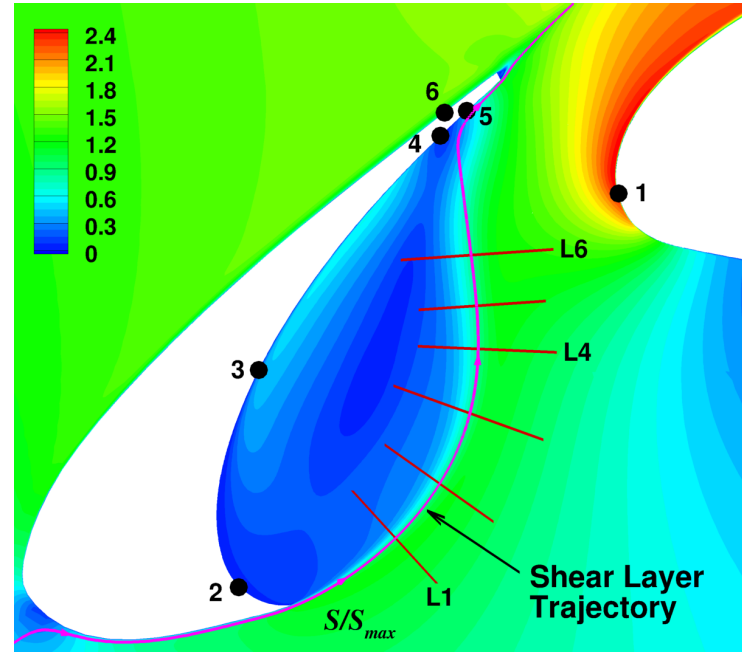

(b) SST DDZ Coarse

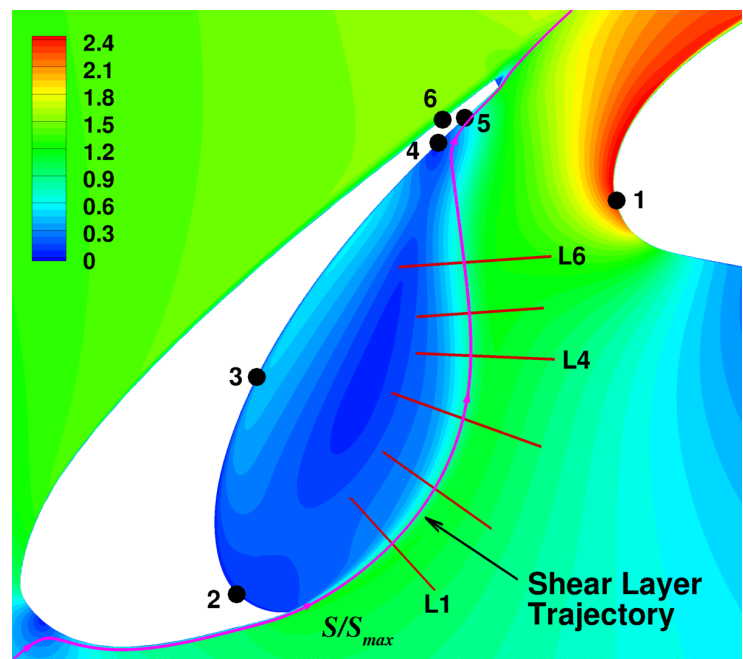

(d) SST DDZ Fine

Figure 8. Magnitude of the planar velocity, $\left|\mathbf{V}_{2 D}^{*}\right| / U_{o}$, around the slat averaged both temporally and in the spanwise direction. $S$ is the distance along the shear layer trajectory, and $S_{\max }$ is the total distance on the trajectory from the cusp to the reattachment point. The lines L1 - L6 define normal cuts through the shear layer, and the pressure spectra is examined at the surface points 1-6. 
portion calculated by the turbulence model. The thin region of high 3-D TKE near the reattachment point and extending to the trailing edge is more pronounced with the blunt trailing edge. Furthermore, the intensity of these fluctuations increases as the grid is refined. The elevated TKE levels are caused by instabilities in the cove shear layer being rapidly distorted as they approach the underside of the slat. ${ }^{19}$ The TKE levels also increase with grid refinement in the section of the shear layer near the cusp. In this region, the shear layer is relatively thin and the most unstable modes are at high frequency, which are much better resolved on the fine grid. Interestingly, the highest TKE levels are observed in the OVERFLOW simulation on the baseline grid but with the higher-order spatial discretization. OVERFLOW could be better resolving some of the higher frequencies or have less artificial dissipation at those frequencies than CFL3D. More detail can be seen in Fig. 11, which shows the 3D TKE and $\left|w^{\prime}\right| /\left(\rho_{o} a_{o}^{2}\right)$ on the four line cuts (L1 - L4) shown in Fig. 8. Both the in- and out-of-plane fluctuations appear to follow similar trends, with the finer resolved calculations exhibiting higher fluctuation levels. The biggest discrepancy occurs on the L2 and L3 line cuts when the higher frequencies that are better resolved on the finer meshes are still growing rapidly. Once the shear layer starts to thicken, the differences between the fluctuation amplitudes decreases. Although the velocity fluctuations all follow similar trends, the pressure fluctuations in the coarser grid simulation become the most intense in the L3 and L4 line cuts as seen in Fig. 11(d). This trend continues further along the shear layer so that even though the most intense velocity fluctuations occur in the fine grid simulation, the opposite is observed for the pressure. This is seen in the contours of the perturbation pressure from the coarse and fine grid simulations that are shown in Fig. 12. The growth rate of the instabilities in the simulations is dependent on the local grid resolution, but also on the upstream history. Furthermore, the eigenfunctions for the instabilities can have behave differently for the pressure and velocities. Hence, the influence of the shear layer velocity fluctuations on the pressure perturbations, including those on the solid surfaces, is not completely understood.

Another way to examine the difference in the scales resolved by the simulations is through an instantaneous view of the vorticity. Fig. 13 compares isosurfaces of the instantaneous streamwise vorticity from the three CFL3D simulations performed on the sequence of grids. The view is from below the high-lift system looking at the slat. All of the simulations exhibit spanwise structures that develop in the shear layer near the cusp but gradually break up and then are rapidly distorted near the reattachment point. Streamwise structures dominate the flow past the reattachment point and past the trailing edge. For all of these features, the richness of the scales increases as the grid is refined, although the biggest difference is between the coarse and baselines meshes.

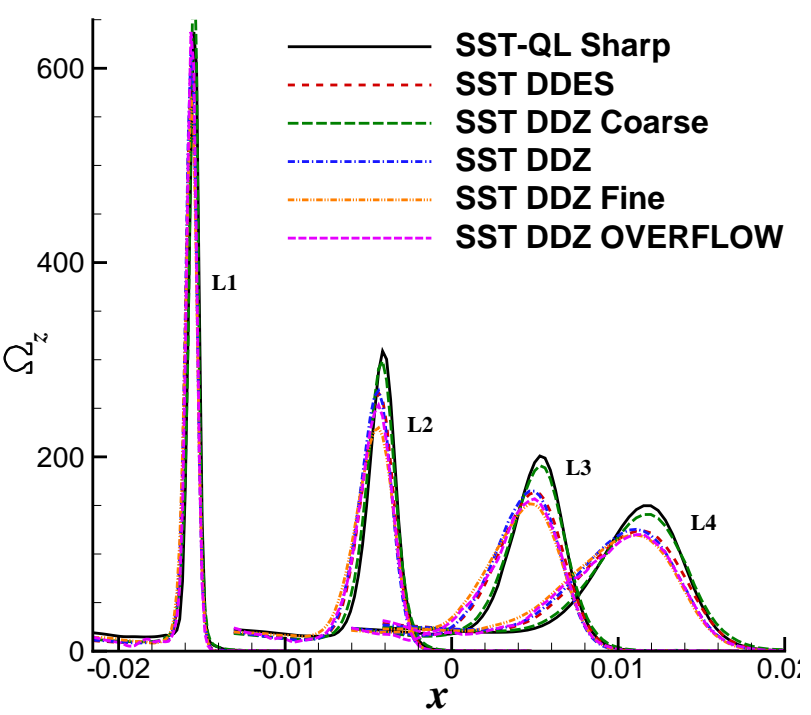

(a) Z Vorticity

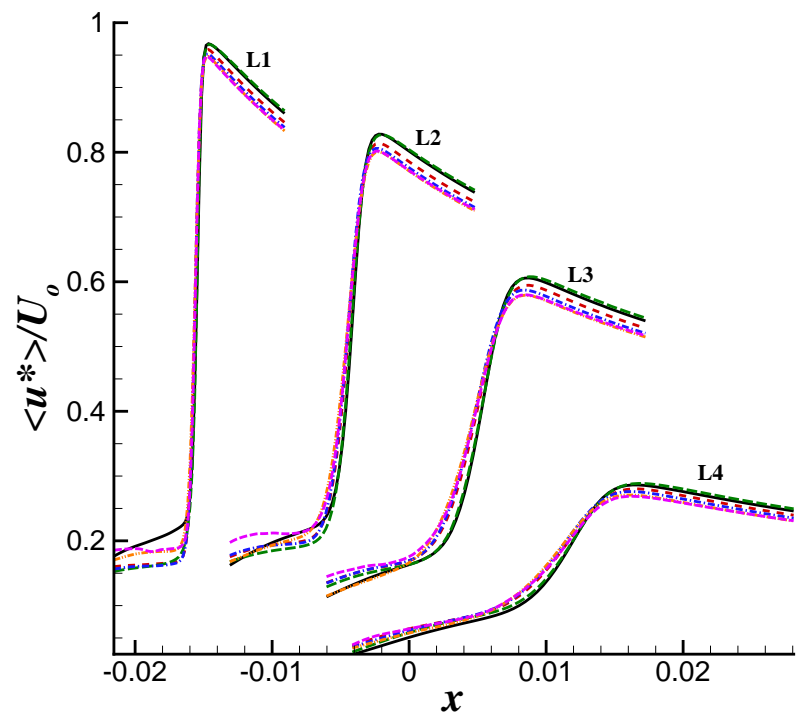

(b) U Velocity

Figure 9. Mean values on line cuts L1-L4 shown in Fig. 8.

The power spectral density (PSD) of the surface pressure at the six surface points identified by black circles in Fig. 8 are presented in Figs. 14 and 15. The power spectral density is plotted against the Strouhal number, $S t=f^{*} c_{s} / U_{o}$, based on the streamwise velocity $U_{o}$, and the slat chord, $c_{s}$. At points 1 and 6, the three different cases in Fig. 14 exhibit similar behavior for $S t<10$. At higher frequencies the tone associated with the shedding from the blunt trailing edge of the slat is noticeably absent in the SST-QL Sharp simulation. The source of the lower frequency tones is still under investigation; but they are fairly robust, appearing in simulations at different Reynolds numbers and with a spanwise flow. They have also been observed in experiments ${ }^{7}$ conducted at Reynolds numbers similar to the 1.7 million used 


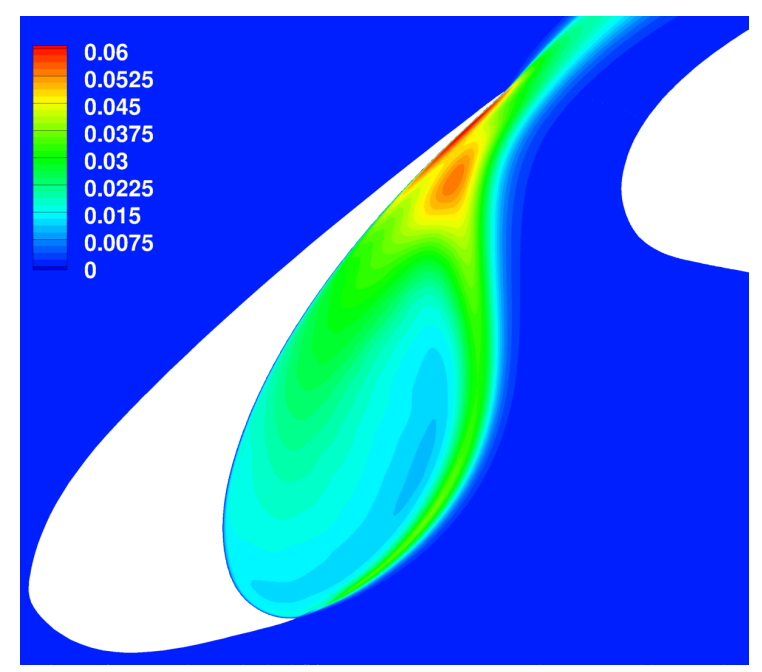

(a) SST-QL Sharp

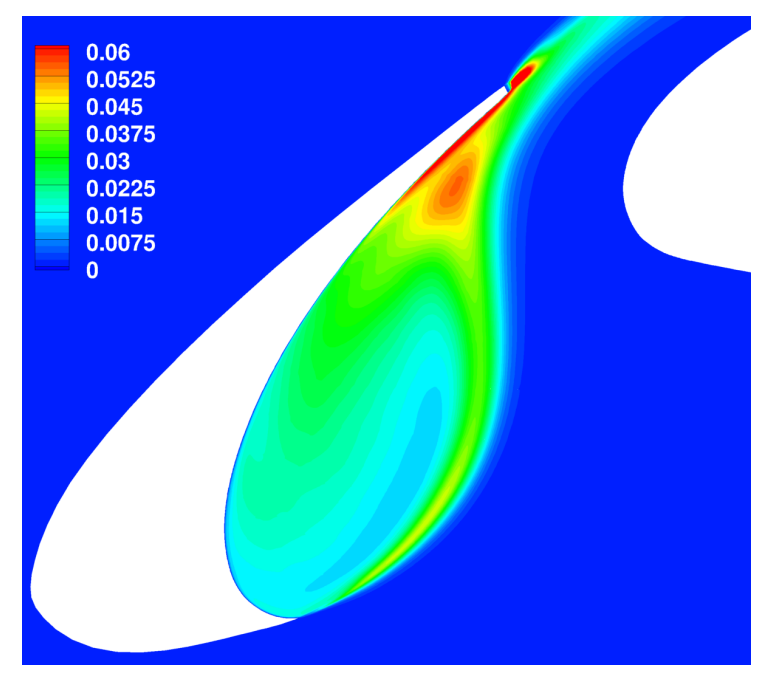

(c) SST DDZ Coarse

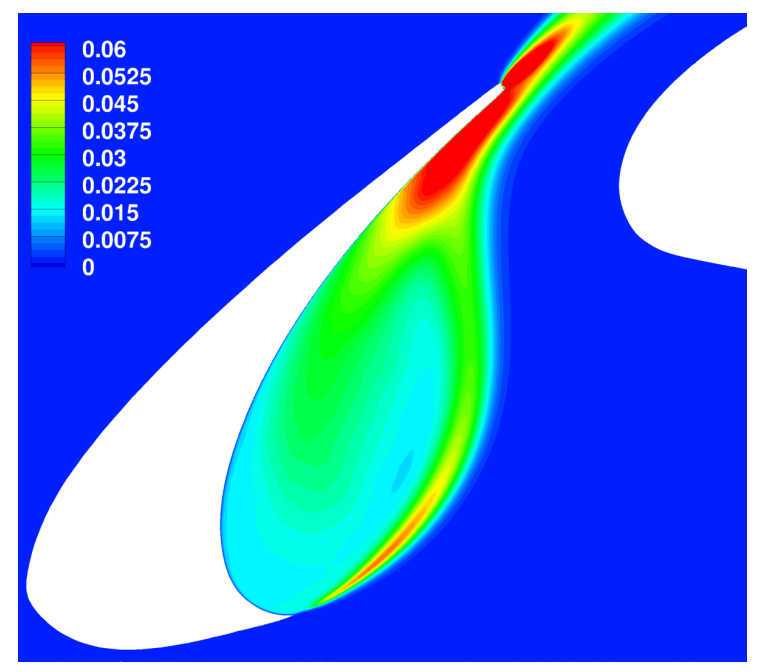

(e) SST DDZ Fine

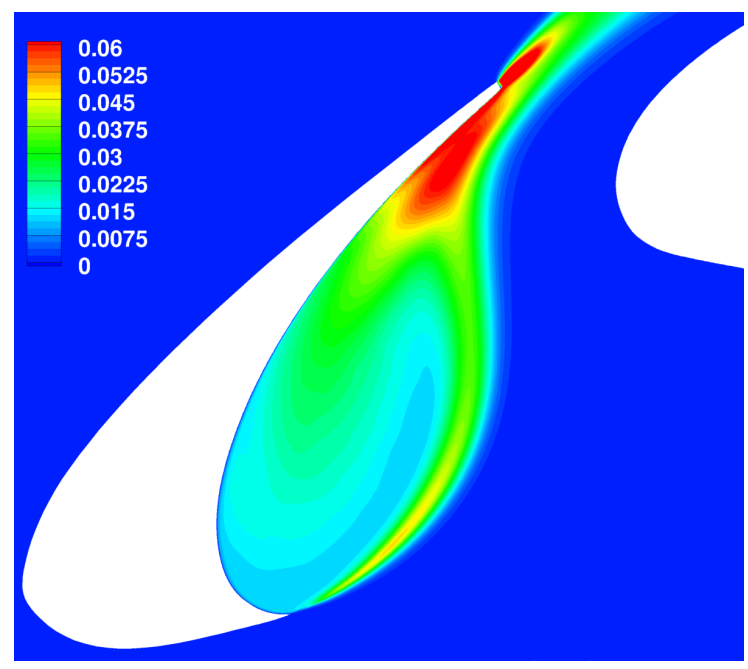

(b) SST DDES

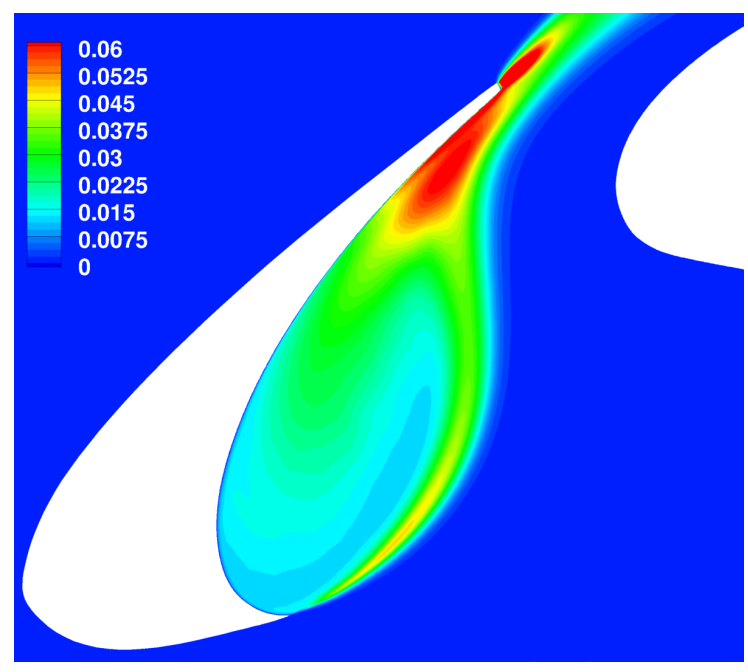

(d) SST DDZ

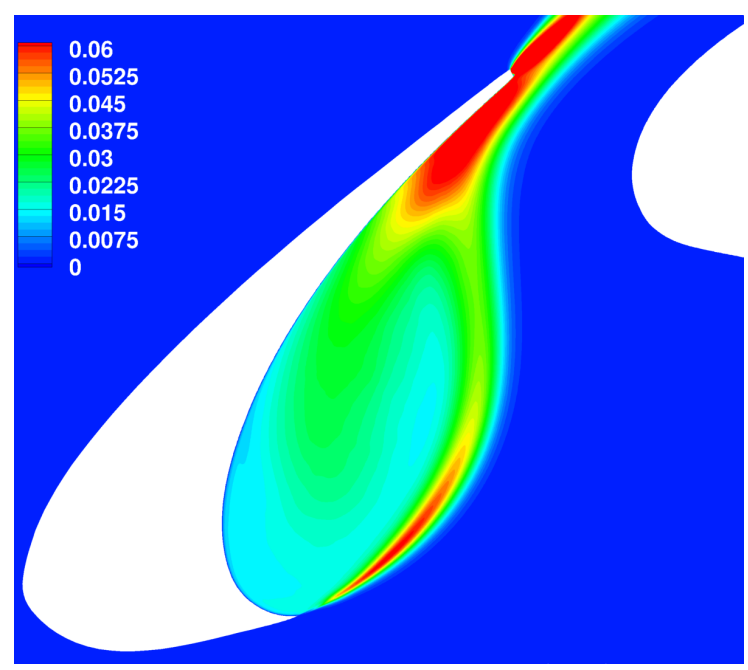

(f) SST DDZ OVERFLOW

Figure 10. 3-D Turbulence kinetic energy normalized by $U_{o}^{2}$ around the slat averaged both temporally and in the spanwise direction. 


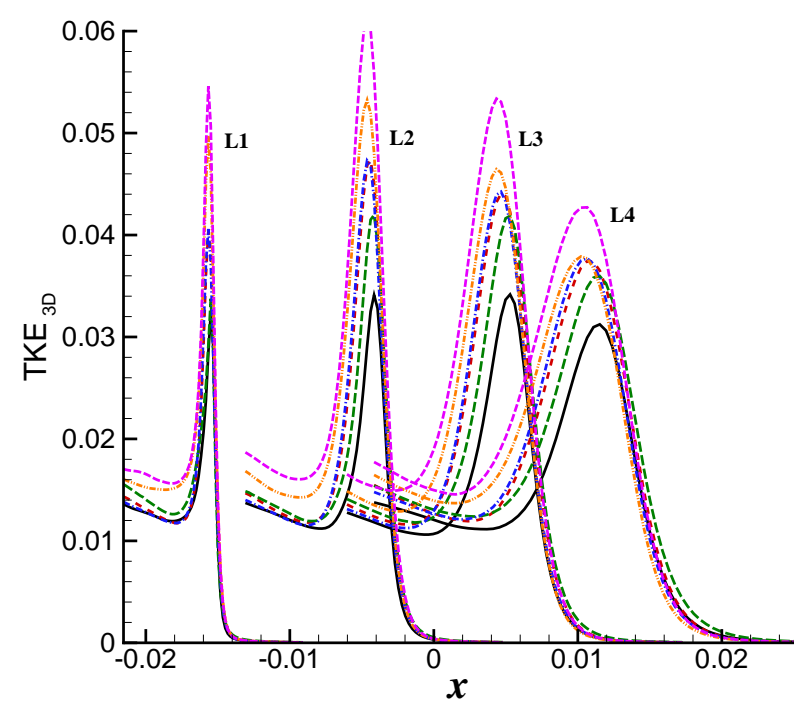

(a) TKE3D

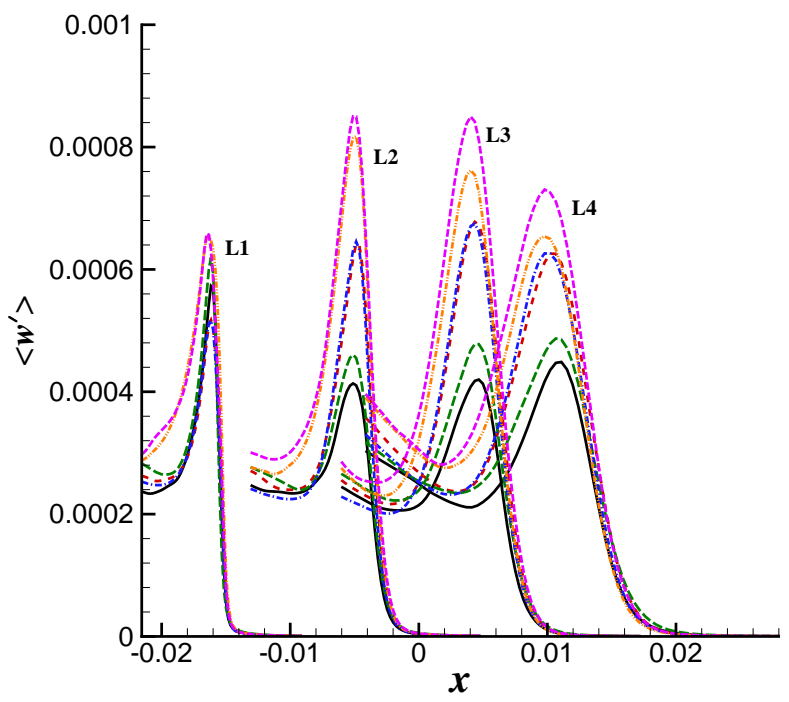

(c) $\left|w^{\prime}\right|$

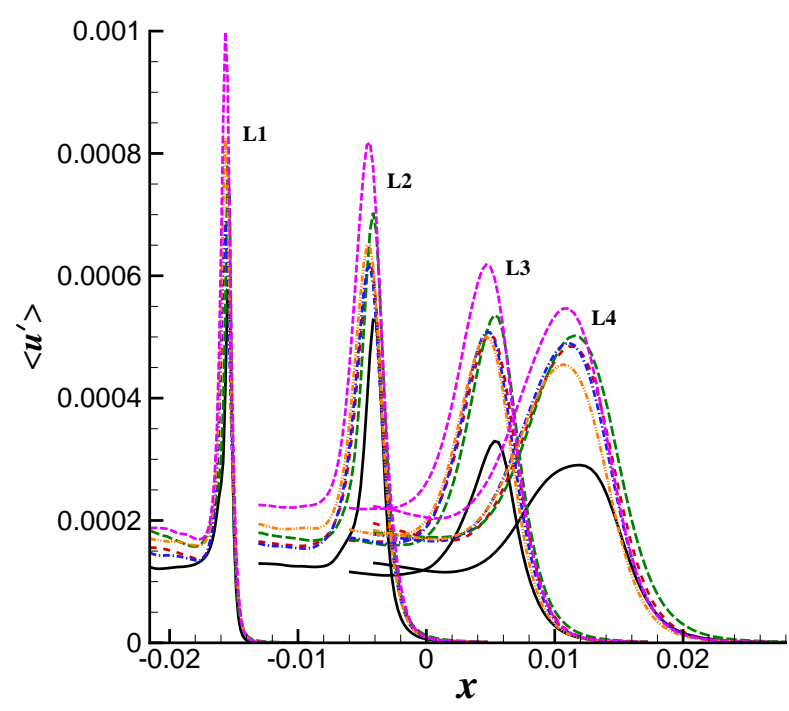

(b) $\left|u^{\prime}\right|$

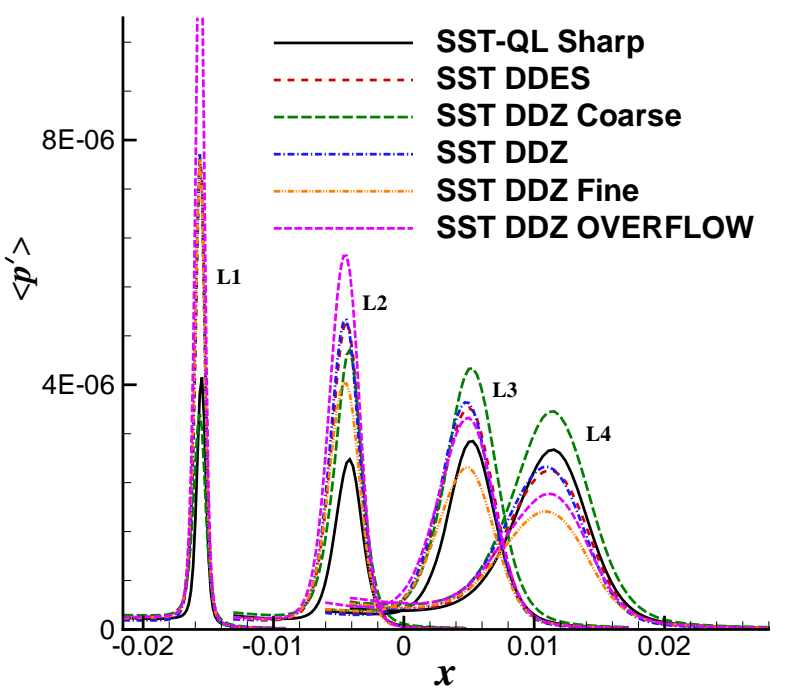

(d) $\left|p^{\prime}\right|$

Figure 11. Fluctuation levels on the L1-L4 line cuts shown in Fig. 8. The velocities are nondimensionalized by $a_{o}$ and the pressure by $\rho a_{o}^{2}$.

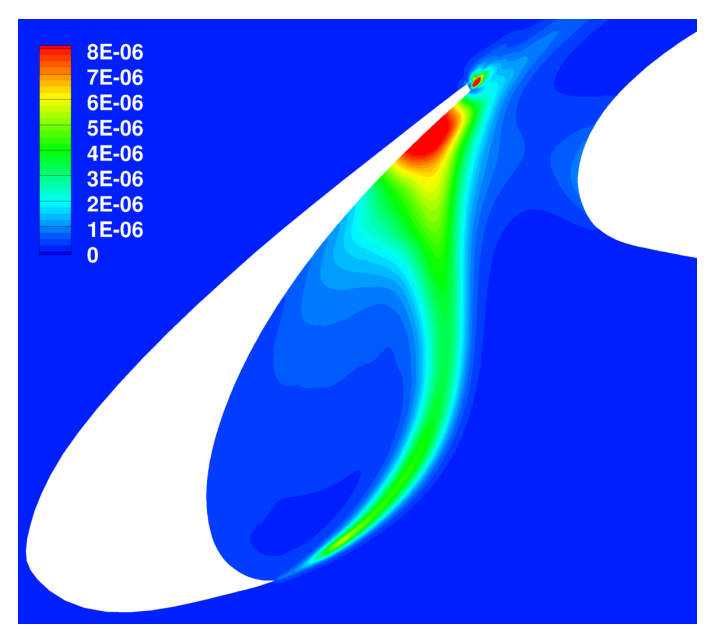

(a) SST DDZ Coarse

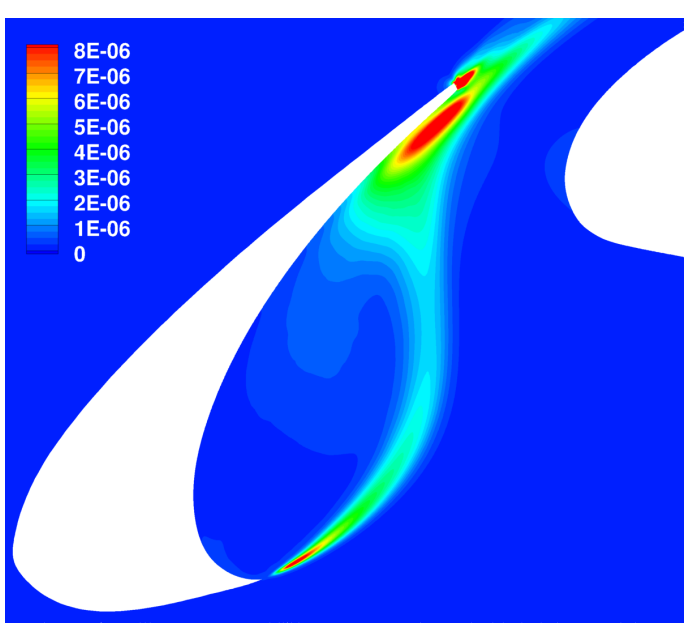

(b) SST DDZ Fine

Figure 12. Perturbation pressure magnitude normalized by $\rho a_{o}^{2}$ around the slat averaged both temporally and in the spanwise direction. 


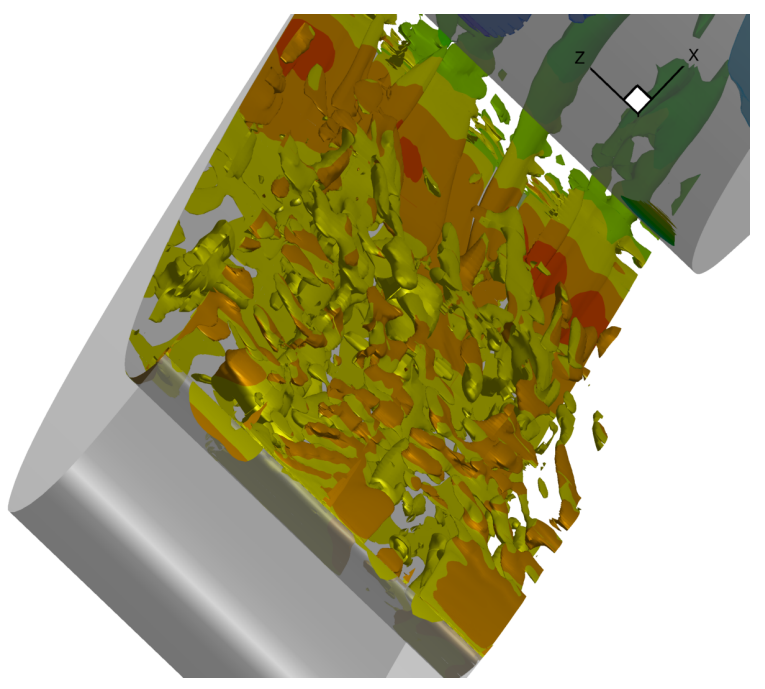

(a) SST DDZ Coarse

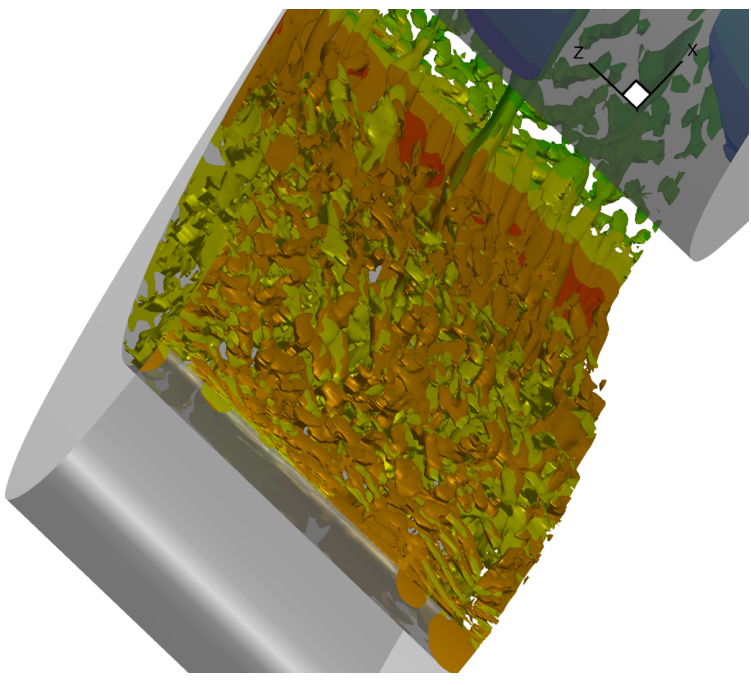

(b) SST DDZ

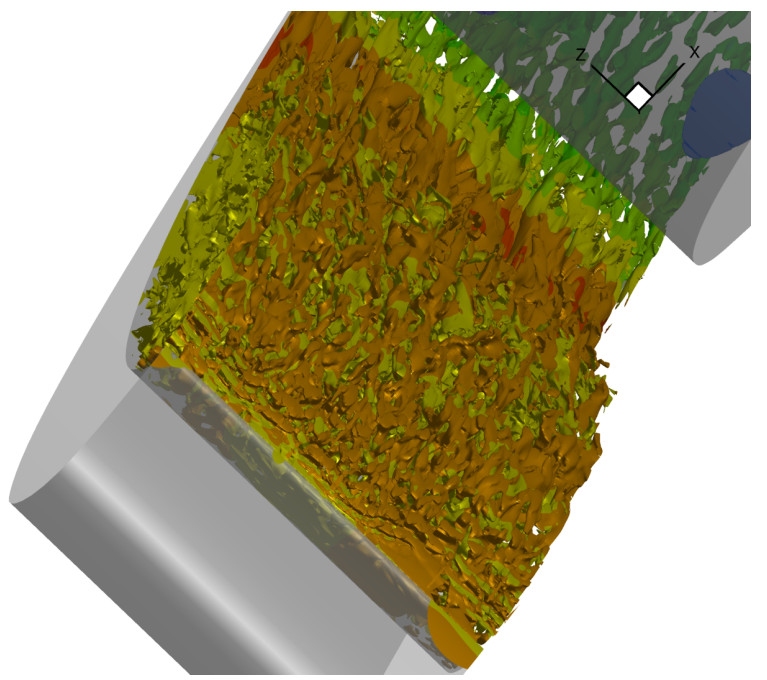

(c) SST DDZ Fine

Figure 13. Instantaneous streamwise vorticity $\left(\zeta_{x}=15\right)$ colored by density. View is from underneath the high-lift system, looking at the slat.

in these simulations. However, the simulations have been run in a fully turbulent manner, which may not be entirely equivalent to the experiments where most of flow around the slat is laminar. Several theories exist as to the source of these tones, but most postulate some sort of resonance similar to Rossiter modes in shallow cavities. ${ }^{7,42}$

Points 1 and 6 are on the upper surface of the slat and on the nose of the main element, respectively; so they are relatively far away from the slat cove shear layer. Hence, the spectra at these points are more representative of the acoustic waves generated by the slat cove unsteadiness rather than being dominated directly by the hydrodynamic fluctuations. This is especially true of point 6 which has the lowest peak amplitude of any of the points.

The tonal features in the SST-QL Sharp simulation are slightly more evident at point 2, but otherwise the three results in Fig. 14(b) are similar to each other. For the other points in the slat cove (points 3-5), the influence of the different trailing edges has a greater impact on the shapes of the PSD curves as the trailing edge is approached. In general, the blunt edge seems to support more energy at high frequencies leading up to the broad hump at $S t=25$ that is associated with trailing-edge shedding being modulated by shear layer unsteadiness. For all of the points, the spectra for the DDES and DDZ simulations are nearly indistinguishable indicating that using RANS over the flap does not significantly affect the fluctuations in the vicinity of the slat.

Similar plots from the grid resolution study shown in Fig. 15 reveal that the coarse grid tends to exhibit higher PSD levels at low frequency, but considerably lower levels at high frequencies. However, the crossover point is around $S t=8$ for points 1 and 6 , whereas it is between 3-4 for the points in the cove. If points 1 and 6 are dominated by acoustic phenomena, then the simulations are trying to resolve waves with a wavelength $\lambda \sim(U \pm a) / f$, whereas 
the wavelength of the vortical waves in the slat cove can be approximated $\lambda \sim U / f$. In the current problem, $U=$ $0.17 a$, so the acoustic wavelength can be as much as five times longer than that of the hydrodynamics. The artificial diffusion in a numerical scheme is strongly dependent on the number of points per wavelength; hence, the propagation of hydrodynamic phenomena will exhibit considerably more diffusion (and phase error) than acoustic waves at the same frequency. Although this propagation effect should allow simulations to more faithfully represent higher frequency acoustic content, it does not address how well the solver can convert hydrodynamic energy into acoustic energy. Indeed, if the conversion is completely linear, the loss of energy in the hydrodynamics would be directly seen in the acoustics generated by those fluctuations. However, if nonlinear interactions between the hydrodynamics gives rise to the noise, the frequency of the acoustics will be considerably higher than that of the vortical phenomena that gave rise to it. This is precisely the form of the acoustic sources in Lighthill's acoustic analogy. ${ }^{43}$ However, the peak at $S t=25$ associated with trailing-edge shedding is the same for both the hydrodynamic and acoustic fluctuations. Clearly, some conversion of energy is occurring in a linear fashion so that the frequency of the acoustics matches that of the hydrodynamics. Although it appears that both linear and nonlinear processes are involved, how to distinguish between the two is not readily apparent.

The conspicuous tone in the OVERFLOW results at $S t=8$ at points 1,2 and 6 corresponds to an acoustic wave with one wavelength across the span. In all the simulations, the periodicity imposed in the spanwise direction results in a cutoff type of phenomena. For frequencies below $S t=8$, only acoustic waves with no spanwise variation can propagate. Hence, all acoustic propagation for low frequencies is two-dimensional. In the OVERFLOW simulation, an instability developed at this critical frequency that eventually overwhelmed the entire solution. Other than the appearance of the peak at this frequency, the sampled data from the OVERFLOW simulation appears to be free of other artifacts of the instability. However, this instability may be why so many subiterations had to be used with the dual-time step algorithm. 


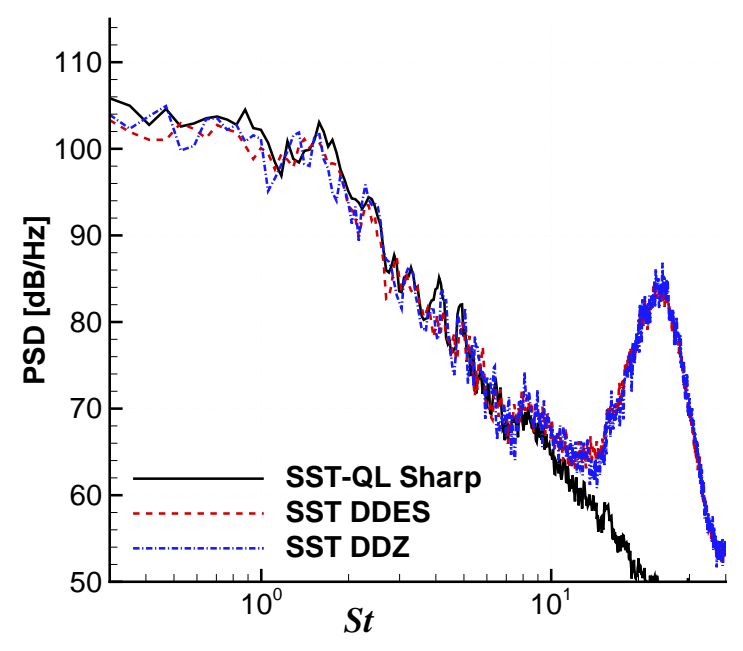

(a) Point 1

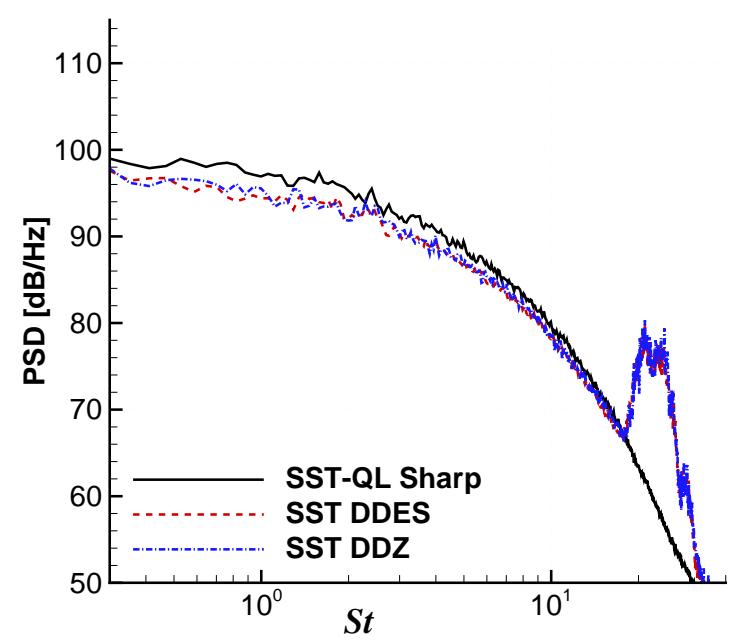

(c) Point 3

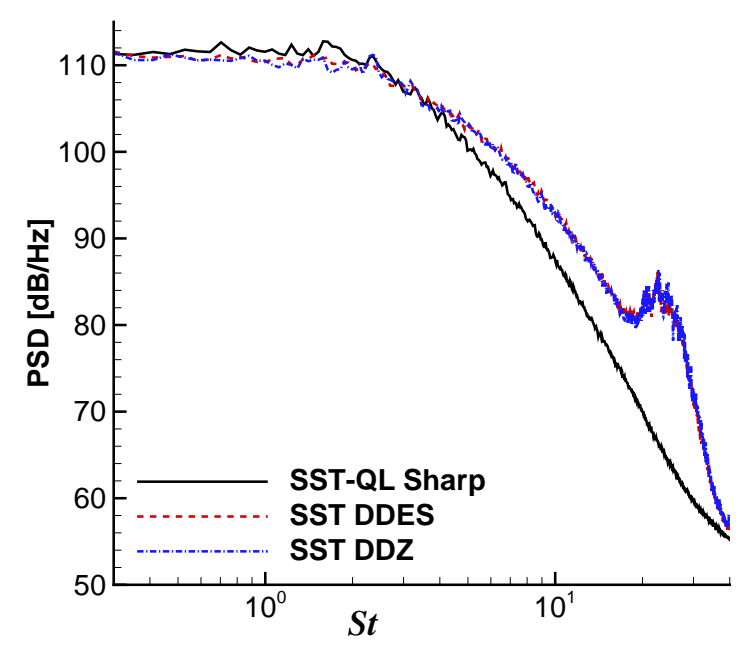

(e) Point 5

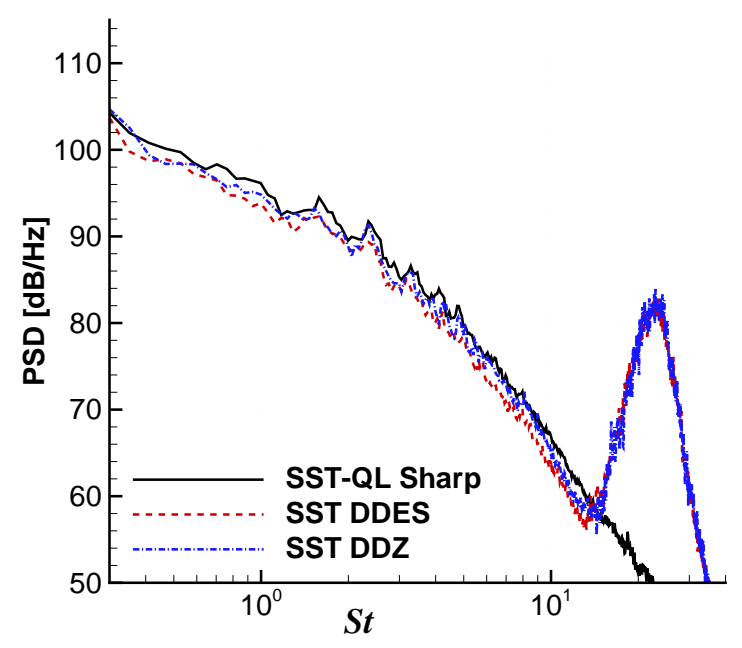

(b) Point 2

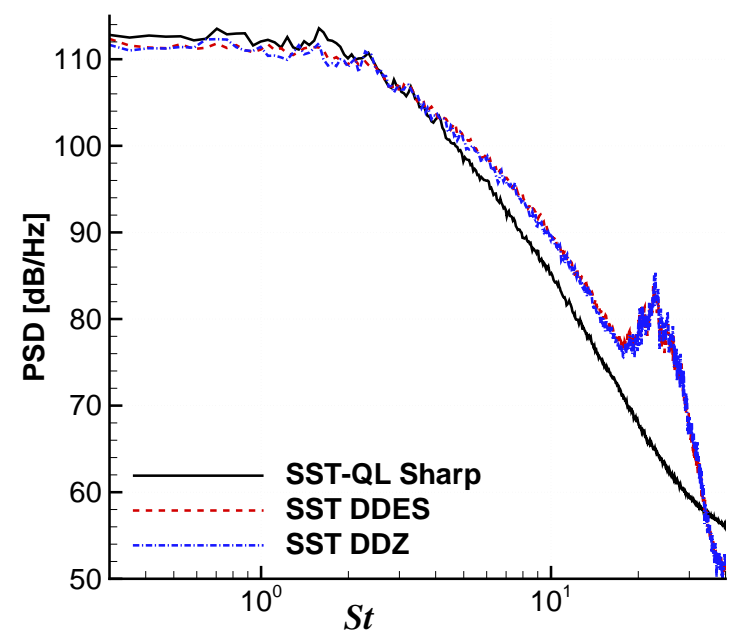

(d) Point 4

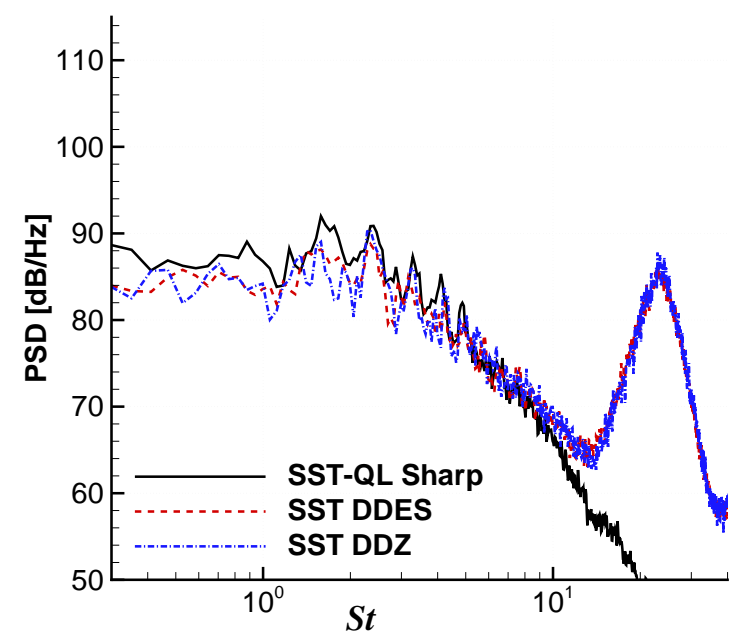

(f) Point 6

Figure 14. Power spectral density versus Strouhal number at the six surface points in Fig. 8. 


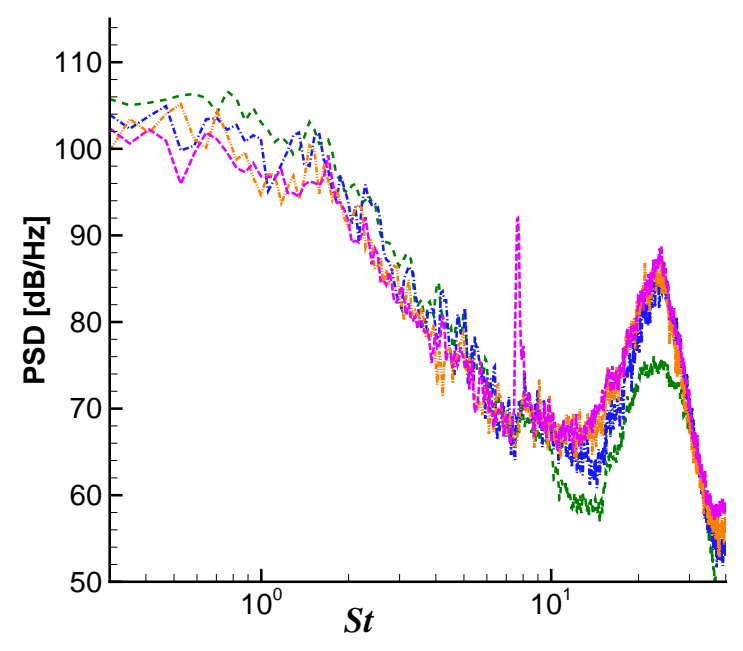

(a) Point 1

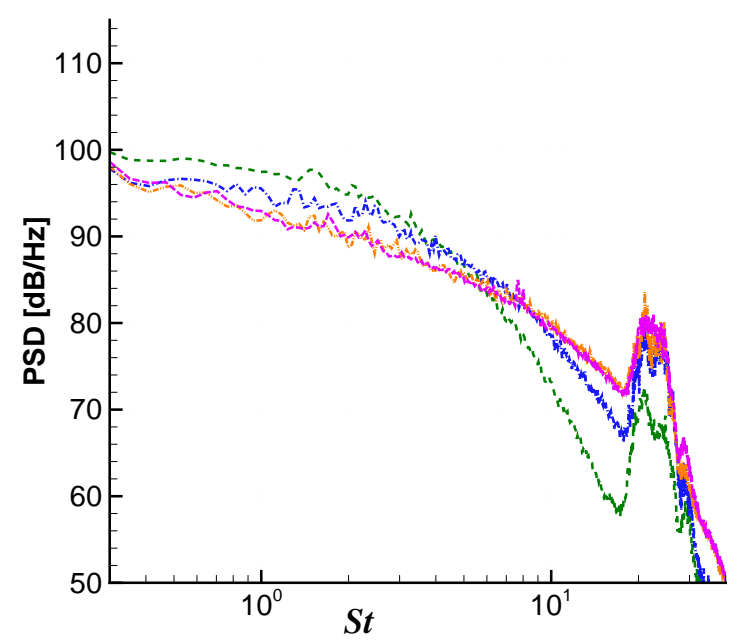

(c) Point 3

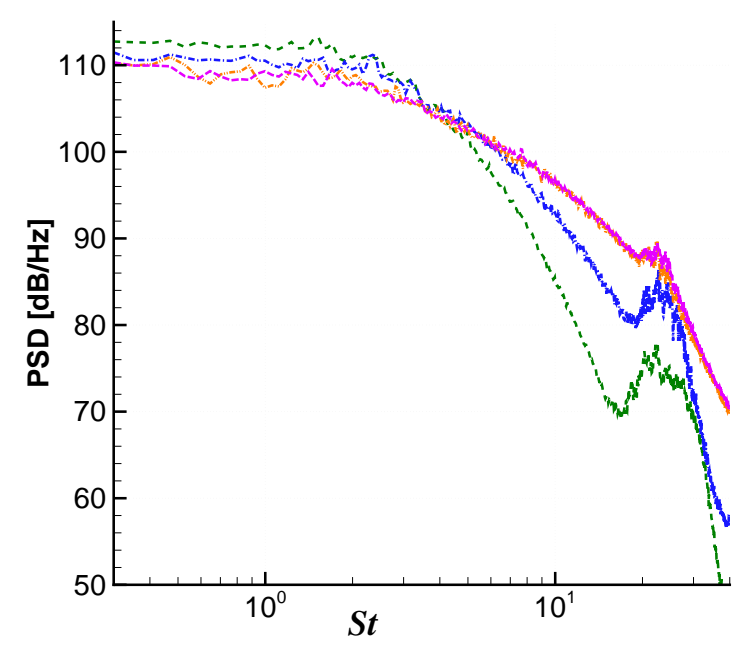

(e) Point 5

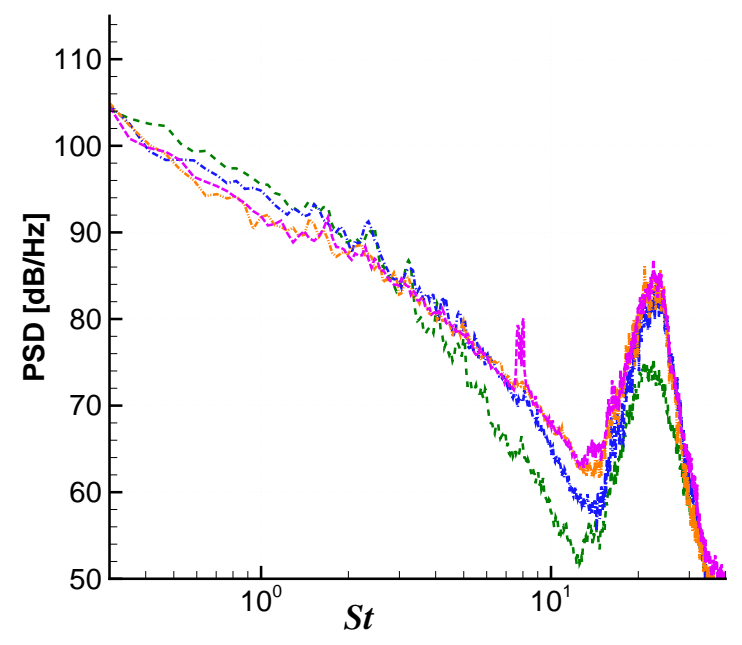

(b) Point 2

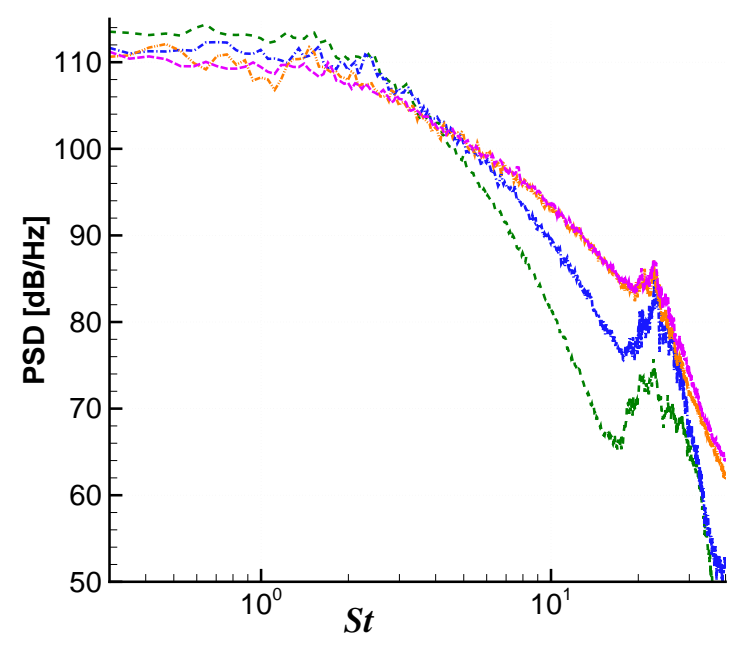

(d) Point 4

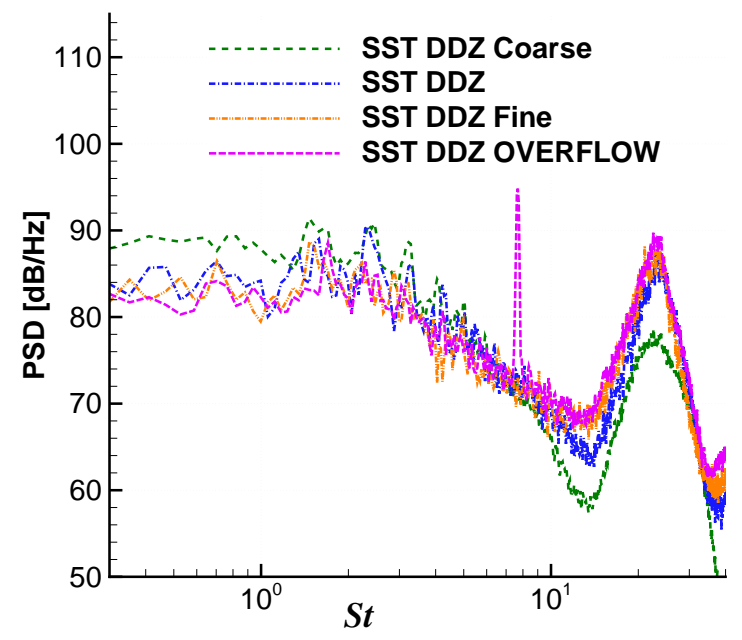

(f) Point 6

Figure 15. Power spectral density versus Strouhal number at the six surface points in Fig. 8. 


\section{Far-Field Acoustics}

The far-field noise was calculated by using the Ffowcs Williams-Hawkings (FW-H) equation ${ }^{44}$ frequency-domain solver described by Lockard. ${ }^{45}$ Calculations were also performed with a time-domain solver, ${ }^{45}$ and the directivity and spectral results were in agreement with those shown here from the frequency-domain solver. Unsteady flow data from the CFD calculations was recorded on the solid surfaces, with the data extracted over the full span used in the CFD calculation. However, only half of the spanwise data were used in the FW-H calculations to avoid artificial interference effects caused by the periodic nature of the simulations. Hence, the noise predictions are for a spanwise segment that is $37 \%$ of the slat chord (approximately 1 in or $2.54 \mathrm{~cm}$ ). Predictions for longer spans could be calculated by using corrections ${ }^{46}$ for the actual span of a body. The temporal record of 39,000 time steps was divided into seven separate segments, where successive segments were overlapped by 50\%. Each segment was run through the FW-H solver independently, and the seven individual results were then averaged.

The directivity is shown in Fig. 16. The distance from the slat trailing edge to the observers is 10 chords. The noise exhibits $1 / r$ decay at this distance as demonstrated in Ref. 23. The directivity was calculated for Strouhal numbers between 0.3 and 10 so that very low- and very high-frequency oscillations that are not adequately represented within the near-field data are excluded. The length of each data segment is sufficient to resolve $S t=0.3$ with approximately six periods. As is evident in the figure, the directivity of the calculated noise is relatively insensitive to the exact geometry and turbulence modeling approach. The case with the sharp trailing edge is similar to that of the coarse grid, and they exhibit higher levels than the other simulations, with the maximum difference approaching a 50\% increase compared to the fine grid result. However, such differences would be around $3.5 \mathrm{~dB}$ on a decibel scale. The shape of the directivity for the SST DDES case is somewhat different from the others, but this is caused by the shedding from the flap which is suppressed in the other cases.

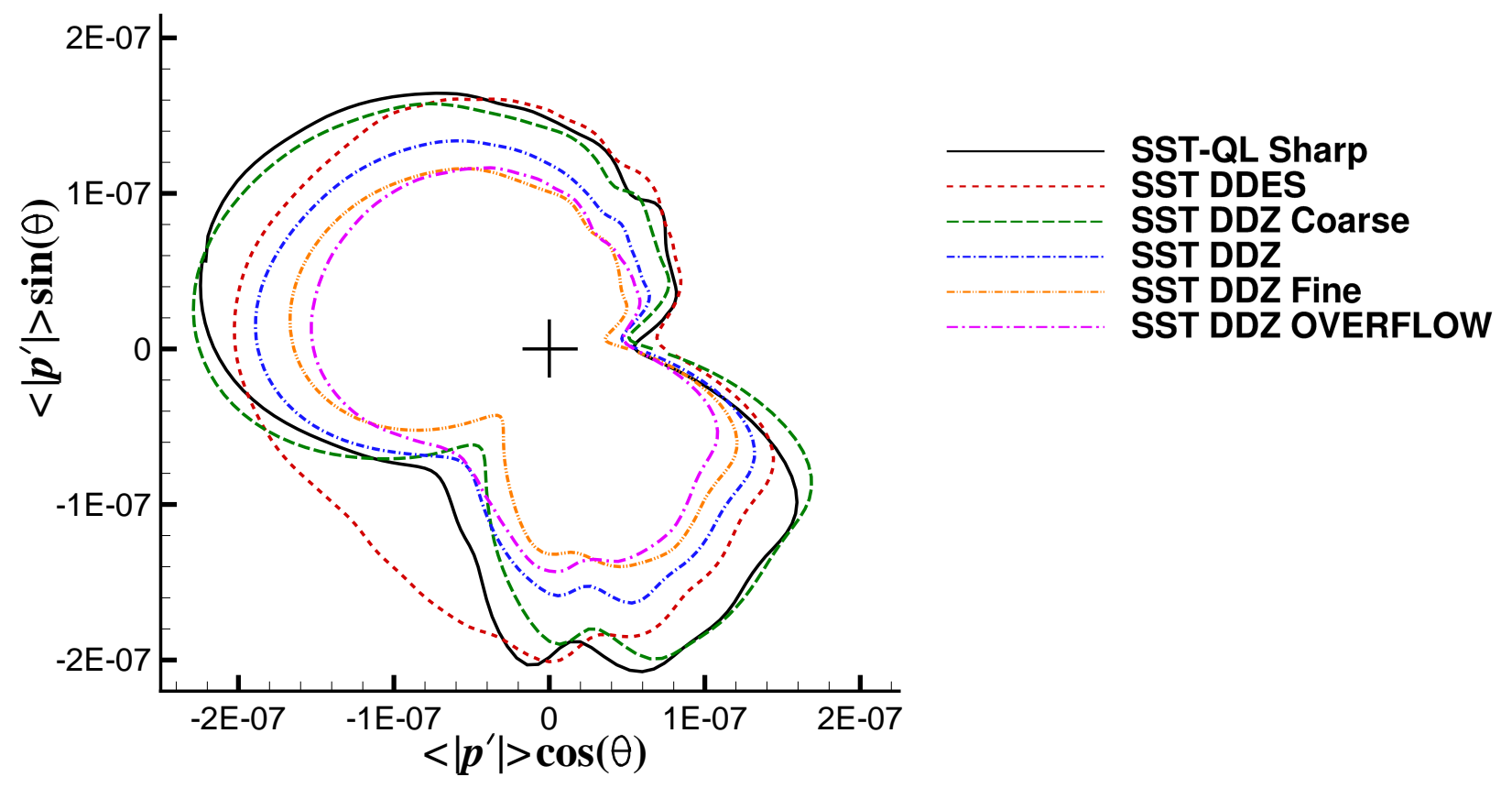

Figure 16. FW-H predictions of the directivity. Observers are 10 chords from the slat trailing edge.

The power spectral density of the pressure at four points between $270^{\circ}$ and $330^{\circ}$ (i.e., within the downstream quadrant below the high-lift system) are presented in Figs. 17 and 18. The current data represent the average of seven realizations with a bin width of $\Delta S t=0.074$ at $U_{\infty}=0.17$, corresponding to $48 \mathrm{~Hz}$. Unfortunately, the simulation data record is not long enough to allow sufficient averaging to smooth the curves as much as desired without using an excessively large bin width. The obvious difference between the sharp and blunt trailing edge cases is the broad spectral hump near $S t=25$ caused by vortex shedding from the blunt slat trailing edge. The blunt-edge cases also exhibit a low frequency tone around $S t=0.6$, the source of which appears to be oscillations in the flap cove interacting with the nose of the flap. The SST DDES and SST DDZ spectra are very similar except for frequencies below $S t=1$, especially in the upstream direction. Noise from the flap is partially responsible for the low-frequency discrepancies, although the relatively short time record also contributes to the large fluctuations observed in this range of frequencies. 
The tonal features in the spectra in Fig. 18(a) appear at similar frequencies, although their amplitudes decrease as the grid is refined. Furthermore, for the finer resolutions, the tones become hard to identify as the angle increases to $330^{\circ}$ in Fig 18(d). In the broadband portion of the spectra, the coarse grid levels may be marginally higher than the others, but the baseline and fine grid results agree with each other and the OVERFLOW result. Again, the tone in the OVERFLOW spectra at $S t=8$ is due to an instability at the frequency corresponding to one acoustic wavelength in the spanwise direction. Overall, the agreement between the acoustic spectra from the different simulations is quite remarkable considering some of the differences observed in the surface pressure spectra. Clearly, the surface pressure spectra in the slat cove do not directly dictate the character of the acoustic spectra.

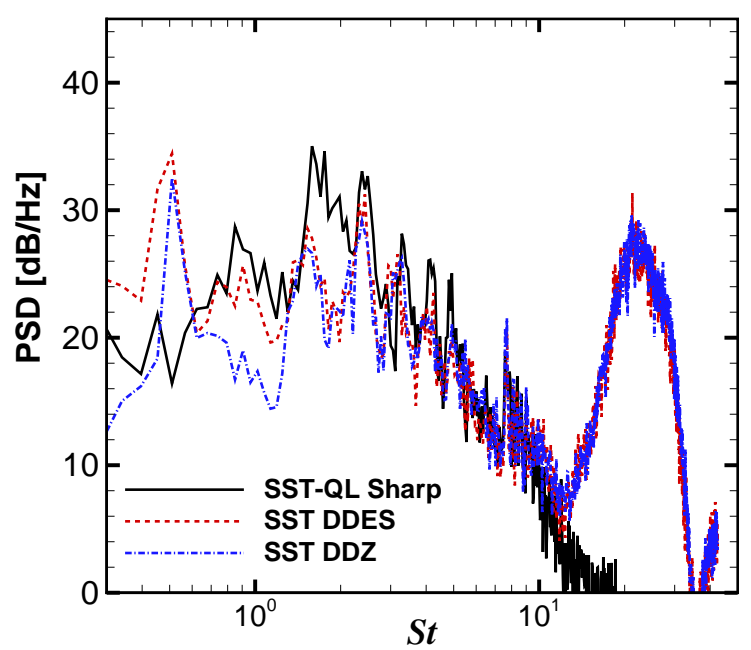

(a) $270^{\circ}$

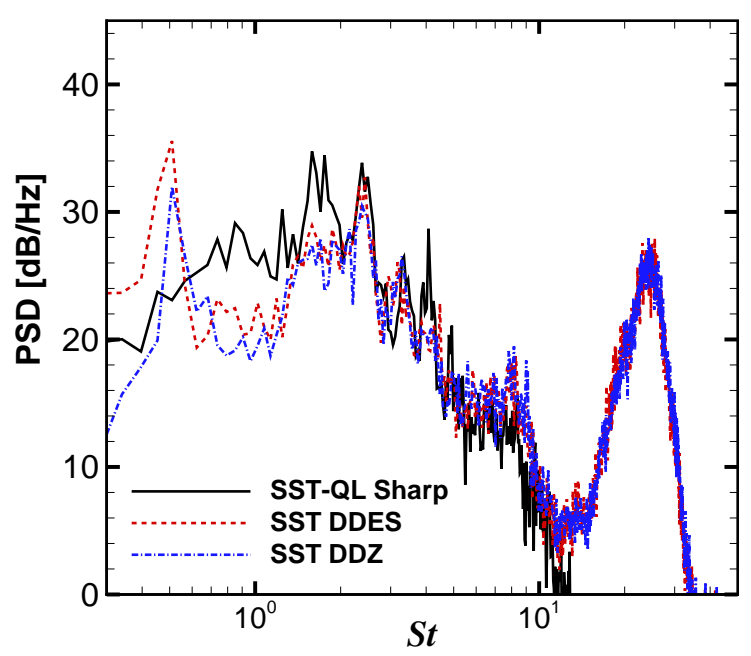

(c) $310^{\circ}$

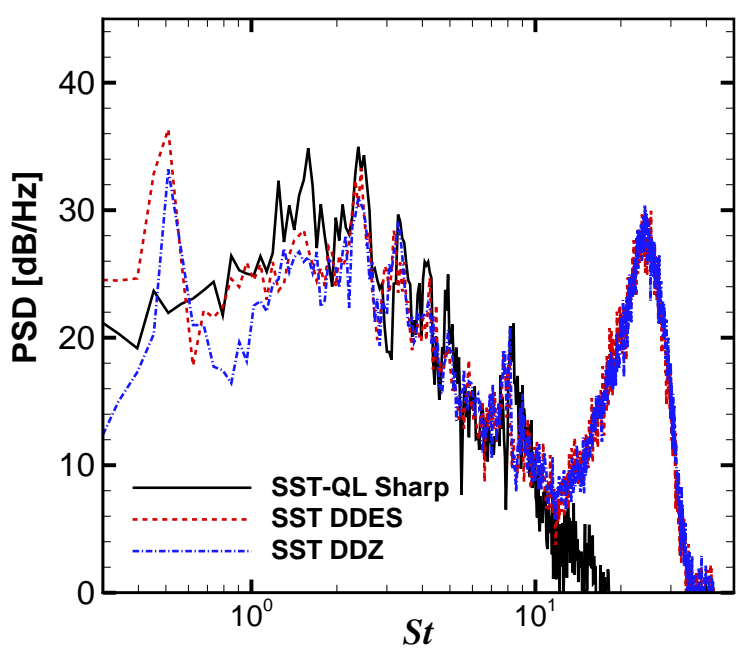

(b) $290^{\circ}$

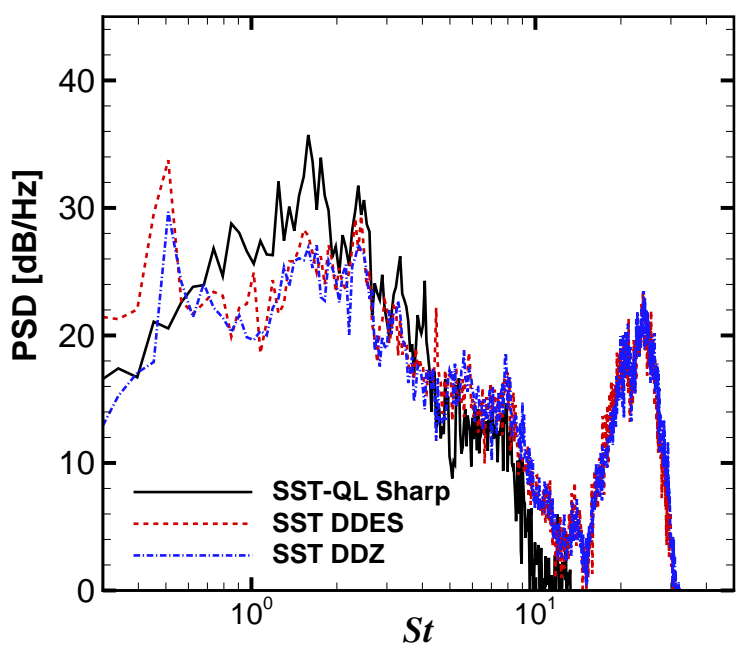

(d) $330^{\circ}$

Figure 17. FW-H predictions of the power spectral density versus Strouhal number at several angles for observers located 10 chords from the slat trailing edge. 


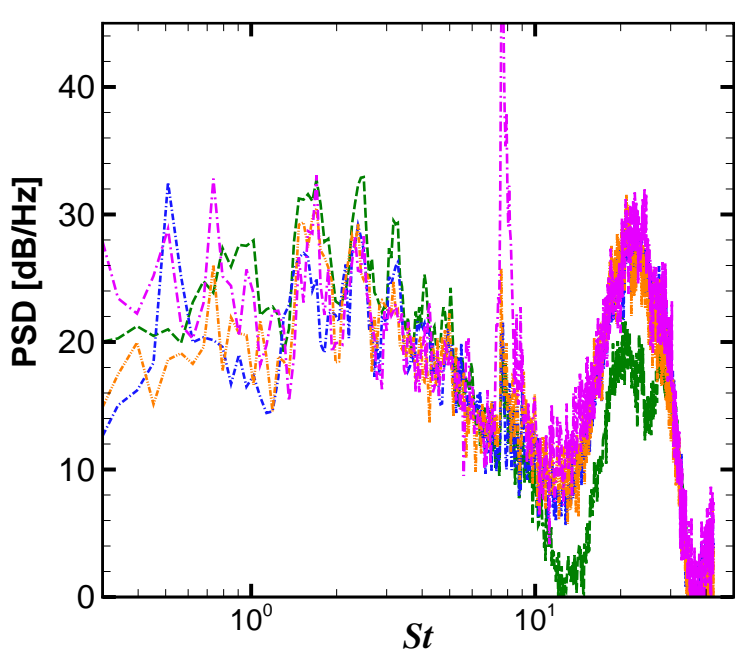

(a) $270^{\circ}$

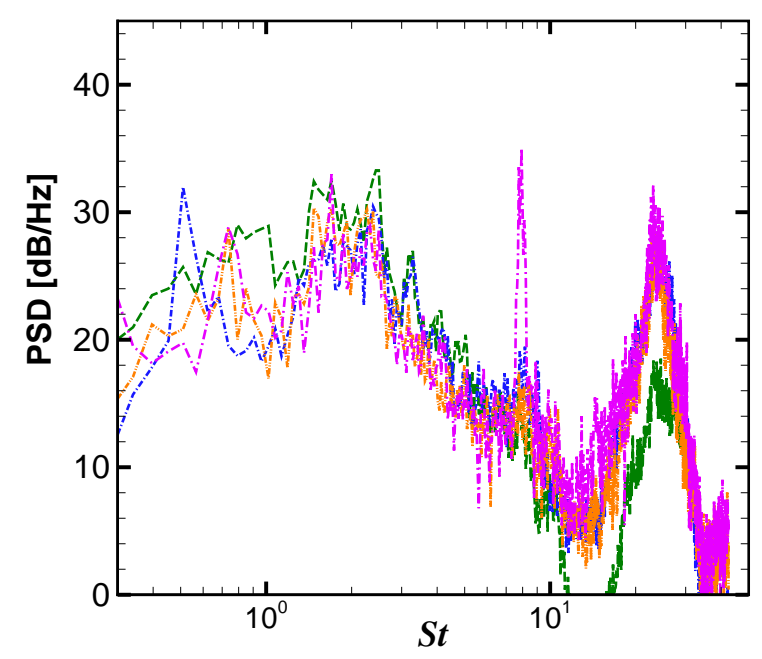

(c) $310^{\circ}$

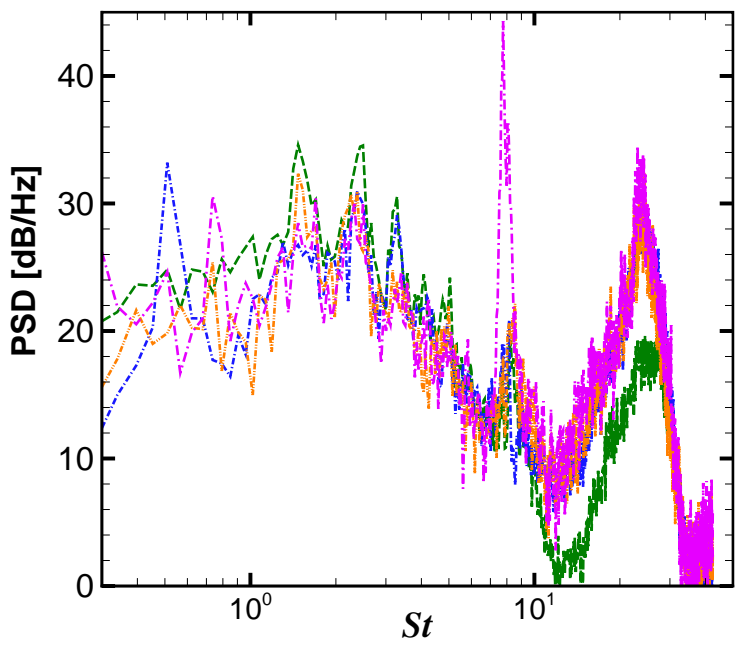

(b) $290^{\circ}$

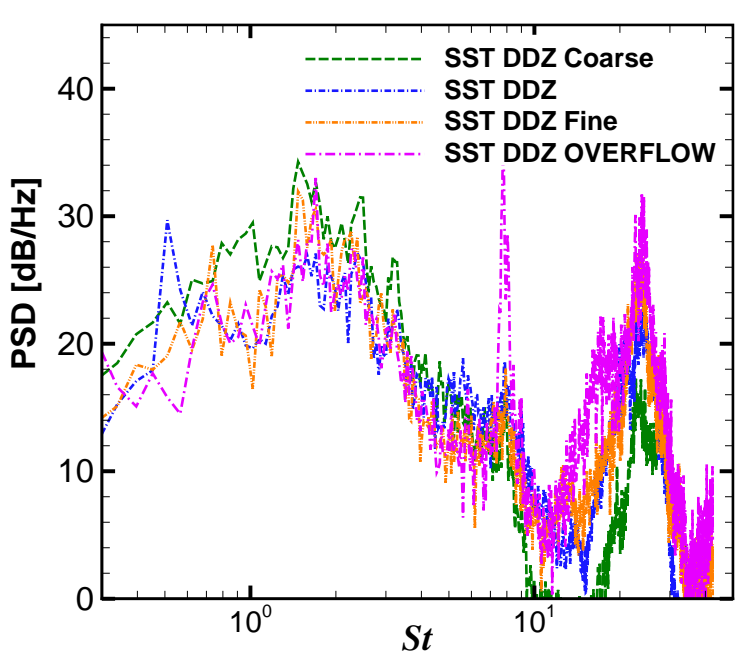

(d) $330^{\circ}$

Figure 18. FW-H predictions of the power spectral density versus Strouhal number at several angles for observers located 10 chords from the slat trailing edge.

\section{Summary and Conclusions}

A sequence of three meshes were used to investigate the influence of grid resolution on unsteady slat simulations. However, the results are not all within the asymptotic regime, so an order property could not be observed in any of the flow quantities examined. The uniform refinement by a factor of two in each coordinate direction used in this study means that each subsequent mesh is eight times larger. Given the expense of unsteady simulations, performing a calculation on a still further refined mesh is not realistic at the current time. The current fine mesh simulation was run on 1,008 cores of an SGI Altix Ice cluster with Intel Westmere nodes and took 100 days of running to collect all the unsteady data. A mesh that is $\sqrt{2}$ finer than the baseline mesh would be much more tractable, but few grid generators can automatically create such a mesh.

The thicker slat trailing edge in the new $30 \mathrm{P} / 30 \mathrm{~N}$ geometry was found to support the typical vortex shedding from a blunt edge as expected, but it also has an influence on the flow in the cove. Although the mean $C_{p}$ distribution is not very different, the development of instabilities in the shear layer is modified. Interestingly, a coarse grid simulation on the new geometry more closely resembles that of the baseline resolution on the old geometry with sharp edges. Both exhibit slower growth of high-frequency instabilities in the shear layer near the cusp, but larger scales become more intense further along the shear layer. Although the low-frequency tonal features in the surface spectra and radiated noise are more distinct in the coarser grid simulations, the high-frequency hump associated with vortex shedding is better captured 
as the grid is refined.

The OVERFLOW simulation using the baseline grid resolution but with higher-order inviscid spatial operators gave nearly identical results to the CFL3D simulation on the fine grid. Although it would seem that using high-order should be much more efficient, the OVERFLOW simulation was beset with stability issues which required considerably tuning of the solver parameters and nearly twice as many subiterations per time step as the low-order, finite-volume code CFL3D. However, once a best practice is established for this type of configuration, a high-order OVERFLOW simulation should be more efficient and desirable. OVERFLOW also offers significantly more flexibility for parallelization (mixed OPENMP/MPI, arbitrary number of cores), and has an automated grid enrichment capability, which could greatly reduce the time needed for grid generation.

Despite the differences observed in the near-field quantities, the spectra of the radiated noise were remarkably similar for all the simulations. The coarse grid and sharp trailing edge case did produce overall levels that were up to $3.5 \mathrm{~dB}$ above those of the fine grid, but this was predominantly caused by stonger tones and frequencies below $S t=1$. Based on the surface pressure spectra, one would expect the noise from the coarse grid simulation to begin to deviate from the others by $S t=4$. Nonetheless, in the $S t=1-10$ range where the broadband component of slat noise dominates, all the spectra had similar levels. However, the finer grids produced considerably less intense tonal features over that frequency range. These tones have been postulated to be similar to Rossiter tones which are observed in rectangular cavities. ${ }^{42}$ Hopefully, the more detailed experiments and additional simulations that are being performed for the BANCIII workshop will more fully elucidate the phenomena responsible for these features. Furthermore, the combined efforts may help to explain the discrepancy between near- and far-field results, which appears to be related to the nonlinear nature of noise generation and the large difference in wavelength between hydrodynamic and acoustic waves in low speed flows. Despite the relative simplicity of the 2-D 30P/30N high-lift system under investigation, it conceals complicated physics and challenges for numerical simulations.

\section{Acknowledgments}

This work was supported by the NASA Fundamental Aeronautics Program's Subsonic Fixed-Wing Project. The authors gratefully acknowledge the assistance of Mr. M. R. Wiese from Vigyan, Inc., who generated the baseline computational grids used during the present study.

\section{References}

\footnotetext{
${ }^{1}$ Hayes, J. A., Horne, W. C., Soderman, P. T., and Bent, P. H., "Airframe Noise Characteristics of a 4.7\% Scale DC-10 Model," AIAA Paper 1997-1594, 1997.

${ }^{2}$ Storms, B. L., Ross, J. C., Horne, W. C., Hayes, J. A., Dougherty, R. P., Underbrink, J. R., Scharpf, D. F., and Moriarty, P. J., "An Aeroacoustic Study of an Unswept Wing with a Three-Dimensional High Lift System," NASA TM 112222, February 1998.

${ }^{3}$ Dobrzynski, W., Nagakura, K., Gehlhar, B., and Buschbaum, A., "Airframe Noise Studies on Wings with Deployed High-Lift Devices," AIAA Paper 1998-2337, 1998.

${ }^{4}$ Storms, B. L., Hayes, J. A., Moriarty, P. J., and Ross, J. C., "Aeroacoustic Measurements of Slat Noise on a Three-Dimensional High-Lift System," AIAA Paper 1999-1957, 1999.

${ }^{5}$ Choudhari, M. M., Lockard, D. P., Macaraeg, M. G., Singer, B. A., Streett, C. L., Neubert, G. R., Stoker, R. W., Underbrink, J. R., Berkman, M. E., Khorrami, M. R., and Sadowski, S. S., "Aeroacoustic Experiments in the Langley Low-Turbulence Pressure Tunnel," NASA TM 211432, February 2002.

${ }^{6}$ Mendoza, F. and Brooks, T., "Aeroacoustic Measurements of a Wing/Slat Model," AIAA Paper 2002-2604, 2002.

${ }^{7}$ Terracol, M., Manoha, E., and Lemoin, B., "Noise Sources Generation in a Slat Cove: Hybrid Zonal RANS/LES Simulation and Dedicated Experiment," AIAA Paper 2011-3203, 2011.

${ }^{8}$ Chow, L. C., Mau, K., and Remy, H., "Landing Gears and High Lift Devices Airframe Noise Research,” AIAA Paper 2002-2408, 2002.

${ }^{9}$ Dobrzynski, W. and Pott-Pollenske, M., "Slat Noise Source Studies for Farfield Noise Prediction,” AIAA Paper 2001-2158, 2001.

${ }^{10}$ Guo, Y., Yamamoto, K., and Stoker, R., "Component Based Empirical Model for High-Lift System Noise Prediction," Journal of Aircraft, Vol. 40, No. 5, 2003, pp. 914-922.

${ }^{11}$ Guo, Y. and Joshi, M., "Noise Characteristics of Aircraft High-Lift Systems," AIAA Journal, Vol. 41, No. 7, 2003, pp. 1247-1256.

${ }^{12}$ Khorrami, M. R., Berkman, M. E., and Choudhari, M. M., "Unsteady Flow Compuations of a Slat with a Blunt Trailing Edge," AIAA Journal, Vol. 38, No. 11, 2000, pp. 2050-2058.

${ }^{13}$ Singer, B. A., Lockard, D. P., and Brentner, K. S., “Computational Aeroacoustic Analysis of Slat Trailing-Edge Flow," AIAA Journal, Vol. 38, No. 9, 2000, pp. 1558-1564.

${ }^{14}$ Khorrami, M. R., Singer, B. A., and Berkman, M. E., "Time-Accurate Simulations and Acoustic Analysis of Slat Free Shear Layer," AIAA Journal, Vol. 40, No. 7, 2002, pp. 1284-1291.

${ }^{15}$ Khorrami, M. R., Singer, B. A., and Lockard, D. P., "Time-Accurate Simulations and Acoustic Analysis of Slat Free Shear Layer: Part II," AIAA Paper 2002-2579, 2002.

${ }^{16}$ Choudhari, M. M., Khorrami, M. R., Lockard, D. P., Atkins, H. L., and Lilley, G. M., "Slat Cove Noise Modeling: A Posteriori Analysis of Unsteady RANS Simulations," AIAA Paper 2002-2468, 2002.

${ }^{17}$ Khorrami, M. R., Choudhari, M. M., and Jenkins, L. M., "Characterization of Unsteady Flow Structures Near Leading-Edge Slat: Part II. 2-D Computations," AIAA Paper 2004-2802, 2004.
} 
${ }^{18}$ Jenkins, L. M., Khorrami, M. R., and Choudhari, M. M., "Characterization of Unsteady Flow Structures Near Leading-Edge Slat: Part I. PIV Measurements," AIAA Paper 2004-2801, 2004.

${ }^{19}$ Choudhari, M. M. and Khorrami, M. R., "Effect of Three-Dimensional Shear-Layer Structures on Slat Cove Unsteadiness," AIAA Journal, Vol. 45, No. 9, 2007, pp. 2174-2186.

${ }^{20}$ Rakhshani, B. and Filippone, A., "Three-Dimensional CFD Analysis of Slat Noise,” AIAA Paper 2008-0015, 2008.

${ }^{21}$ Imamura, T., Enomoto, S., Yokokawa, Y., and Yamamoto, K., "Three-Dimensional Unsteady Flow Computations Around a Conventional Slat of High-Lift Devices," AIAA Journal, Vol. 46, No. 5, 2008, pp. 1045-1053.

${ }^{22}$ Klausmeyer, S. M. and Lin, J., "Comparative Results from a CFD Challenge Over a 2D Three-Element High-Lift Airfoil," NASA TM 112858 , May 1997.

${ }^{23}$ Lockard, D. P. and Choudhari, M. M., “Noise Radiation from a Leading-Edge Slat,” AIAA Paper 2009-3101, 2009.

${ }^{24}$ Imamura, T., Enomoto, S., Yokokawa, Y., and Yamamoto, K., "Simulation of the Broadband Noise from a Slat Using Zonal LES/RANS Hybrid Method," AIAA Paper 2007-0226, 2007.

${ }^{25}$ Dierke, J., Appel, C., Siebert, J., Bauer, M., Siefert, M., and Ewert, R., “3D Computation of Broadband Slat Noise from Swept and Unswept High-Lift Wing Sections," AIAA Paper 2011-2905, 2011.

${ }^{26}$ Bauer, M. and Ewert, R., "Slat Noise Prediction using Discontinuous Galerkin Method and Stochastic Turbulent Sound Source," AIAA Paper 2010-3832, 2010.

${ }^{27}$ Lockard, D. P. and Choudhari, M. M., "The Effect of Cross Flow on Slat Noise,” AIAA Paper 2010-3835, 2010.

${ }^{28}$ Lockard, D. P. and Choudhari, M. M., "The Variation of Slat Noise with Mach and Reynolds Numbers," AIAA Paper 2011-2910, 2011.

${ }^{29}$ Choudhari, M. M., Lockard, D. P., Khorrami, M. R., and Mineck, R. E., "Slat Noise Simulations: Status and Challenges," Proceedings of Inter-Noise 2011, ed. Hiroyuki Imaizumi, Osaka, Japan, Sept. 4-7, 2011.

${ }^{30}$ Kaepernick, K., Koop, L., and Ehrenfried, K., "Investigation of the Unsteady Flow Field inside a Leading Edge Slat Cove," AIAA Paper 2005-2813, 2005.

${ }^{31}$ Andreou, C., Graham, W., and Shin, H. C., “Aeroacoustic Study of Airfoil Leading Edge High-Lift Devices,” AIAA Paper 2006-2515, 2006.

${ }^{32}$ Imamura, T., Ura, H., Yokokawa, Y., Hirai, T., and Yamamoto, K., "Numerical and Experimental Research of Low-Noise Slat using Simplified High-lift Model,” AIAA Paper 2008-2918, 2008.

${ }^{33}$ Lockard, D. P. and Choudhari, M. M., "The Influence of Realistic Reynolds Numbers on Slat Noise Simulations," AIAA Paper 2012-2101, 2012.

${ }^{34}$ Thomas, J. L., Krist, S., and Anderson, W., "Navier-Stokes Computations of Vortical Flows Over Low-Aspect-Ratio Wings," AIAA Journal, Vol. 28, No. 2, 1990, pp. 205-212.

${ }^{35}$ Nichols, R. H., Tramel, R. W., and Buning, P. G., "Solver and Turbulence Model Upgrades to OVERFLOW 2 for Unsteady and High-Speed Applications," AIAA 2006-2824, 2006.

${ }^{36}$ Rumsey, C. L., Biedron, R. T., and Thomas, J. L., “CFL3D: Its History and Some Recent Applications," NASA TM 112861, May 1997, presented at the Godonov's Method for Gas Dynamics Symposium, Ann Arbor, MI.

${ }^{37}$ Nichols, R., Tramel, R., and Buning, P., "Solver and Turbulence Model Upgrades to OVERFLOW 2 for Unsteady and High-Speed Applications," AIAA Paper 2006-2824, 2006.

${ }^{38}$ Strelets, M., "Detached Eddy Simulation of Massively Separated Flows," AIAA Paper 2001-0879, 2001.

${ }^{39}$ Menter, F. R., "Two-equation Eddy-Viscosity Turbulence Models for Engineering Applications," AIAA Journal, Vol. 32, No. 8, 1994, pp. 15981605.

${ }^{40}$ Vatsa, V. N. and Lockard, D. P., "Assessment of Hybrid RANS/LES Turbulence Models for Aeroacoustics Applications,” AIAA Paper 20104001, 2010.

${ }^{41}$ Spalart, P. R. and Allmaras, S., "A One-Equation Turbulence Model for Aerodynamic Flows,” Recherche Aerospatiale, Vol. 1, No. 1, 1994, pp. 5-21.

${ }^{42}$ Deck, S. and Laraufie, R., "Numerical Investigation of the Flow Dynamics Past a Three-element Aerofoil," Journal of Fluid Mechanics, Vol. 732, 2013, pp. 401-444.

${ }^{43}$ Lighthill, M. J., "On Sound Generated Aerodynamically, II: Turbulence as a Source of Sound," Proceedings of the Royal Society, Vol. A222, 1954, pp. 1-32.

${ }^{44}$ Ffowcs Williams, J. E. and Hawkings, D. L., "Sound Generation by Turbulence and Surfaces in Arbitrary Motion," Philosophical Transactions of the Royal Society, Vol. A264, No. 1151, 1969, pp. 321-342.

${ }^{45}$ Lockard, D. P., “A Comparison of Ffowcs Williams-Hawkings Solvers for Airframe Noise Applications,” AIAA Paper 2002-2580, 2002.

${ }^{46}$ Seo, J. H., Chang, K. W., and Moon, Y. J., “Aerodynamic Noise Prediction for Long-Span Bodies,” AIAA Paper 2006-2573, 2006. 